\title{
Breaking wave loads at vertical seawalls and breakwaters
}

\author{
Giovanni Cuomo ${ }^{1}$, William Allsop ${ }^{1 \& 2}$, Tom Bruce ${ }^{3} \&$ \\ Jonathan Pearson ${ }^{4}$
}

\author{
${ }^{1}$ HR Wallingford, Howbery Park, Wallingford, OX10 8BA, UK; \\ ${ }^{2}$ Department of Civil and Environmental Engineering, University of Southampton \\ ${ }^{3}$ School of Engineering \& Electronics, University of Edinburgh, King's Buildings, Edinburgh, EH9 3JL, UK \\ ${ }^{4}$ The University of Warwick, Coventry, CV4 7AL, UK.
}

Published in Coastal Engineering, 57 (4), (2010)

\section{Abstract}

This paper presents recent advances in knowledge on wave loads, based on experimental work carried out in the CIEM / LIM large flume at Barcelona within the framework of the VOWS (Violent Overtopping by Waves at Seawalls) project. Both quasi-static and impact wave forces from the new data set have been compared with predictions by empirical and analytical methods. The scatter in impact forces has been found to be large over the whole range of measurements, with no existing method giving especially good predictions. Based on general considerations, a simple and intuitive set of prediction formulae has been introduced for quasi-static and impact forces, and overturning moments, giving good agreement with the new measurements. New prediction formulae have been compared with previous measurements from physical model tests at small and large scale, giving satisfactory results over a relatively wide range of test conditions. The time variation of wave impacts is discussed, together with pressure distribution up the wall, which show that within experimental limitations the measured pressures are within existing limits of previous study

This is the author's version of a work that was accepted for publication in Coastal Engineering. Changes resulting from the publishing process, such as peer review, editing, corrections, structural formatting, and other quality control mechanisms may not be reflected in this document. Change may have been made to this work since it was submitted for publication. A definitive version was subsequently published in Coastal Engineering, Volume 57, Issue 4, April 2010. DOI: 10.1016/j.coastaleng.2009.11.005

\section{Keywords}

Impulsive loads, Seawalls, Caisson Breakwaters, Wave breaking, Pressure Impulse, Wave impacts

\section{Introduction}

It has long been recognised that wave loads on vertical seawalls and breakwaters (including steeply-battered and composite walls) may vary between slowly-acting, 'pulsating' loads, and more intense but shorter lasting 'impact' (or 'impulsive') loads. Loads from non-breaking (pulsating) waves can be predicted with reasonable confidence by empirical formulae, but wave impact loads have always been troublesome to designers, as impact loads can be 10-50 times greater in magnitude than pulsating loads, see Kirkgoz (1982) Allsop et al (1996c) or McKenna (1997). Very short duration loads may, however, not persist for long enough to cause any noticeable movement or damage, so wave impact loads are not always explicitly or appropriately treated 
in design or analysis. Improved awareness in recent years of the occurrence and effects of wave impact loads, including failures (Oumeraci, 1994; Franco, 1994), has focused attention on the need to include dynamic responses to wave impact loads in the analysis of loadings (see, e.g. Oumeraci et al., 2001 and Allsop, 2000). Recent experimental work has therefore focused more strongly on recording and analysing violent wave impacts.

This paper reports measurements of impulsive wave loads on a steeply-battered (10:1) wall from tests in the large wave flume at Barcelona under the Violent Overtopping by Waves at Seawalls (VOWS) project. From those loads, it derives a set of simple formulae for prediction of wave loads on vertical and near-vertical walls with steep foreshores, subject to breaking waves.

A short literature review is summarised in §2, including historical contributions from the beginning of the 20th Century. The new experiments are described in $\$ 3$ and measurements compared to methods in literature (§4). Based on the analysis of relative importance of the main parameters (§5), a new set of formulae is introduced for both impact (\$6) and quasi-static (\$7) loads and compared with the new set of measurements. Based on the Mitsuyasu "compression model law" (1966), a semi-empirical scaling method is applied to impact pressures at different scales (§8) then predictions of impact forces by the new formulae are compared to measurements from physical model tests under the PROVERBS research project at both small and large scale.

Semi-empirical expressions for the distribution of positive (shoreward) quasi-static pressures up the wall are also presented in §9. Pressure and force impulses recorded during physical model tests are compared with prediction by pressure impulse theory, and a semi-empirical relation is given for the estimation of impact risetimes corresponding to a given impact magnitude (§10). Finally, conclusions and an assessment of the next challenges are given in $\S 11$.

\section{Literature review}

Much research has been carried out on wave forces on sea walls since Stevenson (1874) and Gaillard (1904) conducted the first observational studies at the end of the 19th century. Despite efforts by researchers worldwide, assessment of wave loads to be used in design of breakwaters or seawalls subject to breaking wave attack is still an open issue, mainly due to the highly stochastic nature of wave impact forces. Under the European PROVERBS project, Oumeraci et al. (2001) summarise work on wave loads with suggested method for quasi-static and impulsive loads. Cuomo (2005) reviewed prediction methods for wave-induced forces on coastal structures, including caisson breakwaters and seawalls. A brief summary is given of selected works by previous researchers.

Based on field measurements, Hiroi (1920) suggested the following tentative prediction formula for the average wave pressure from non-breaking waves:

$$
P=1.5 \cdot \rho \cdot g \cdot H_{D}
$$

where $\mathrm{H}_{\mathrm{D}}$ is the design wave height. The methodology assumes that the pressure given by Equation 1 acts uniformly over the full height of an upright section, or to an elevation of 1.25 times the wave height above the s.w.l., whichever is less.

Sainflou (1928) found good agreement between field measurements of wave pressures on vertical walls with those predicted by non-linear theory for standing (i.e. non breaking) regular waves. Whilst still useful for pulsating wave loads, Sainflou's method do not give impulsive loads. 
Work by Bagnold (1939) laid foundations for much subsequent research on wave impacts on coastal structures. Impact pressures were observed to vary greatly even for fixed nominal conditions, but the pressure impulse (defined as the integral of pressure over time) was far more repeatable. Bagnold noted the importance of entrained air, observing that pressures were greatest when the amount of air trapped by the wave as it met the wall was least, but not zero.

Minikin (1963), used Bagnold's piston model to develop a prediction method for the estimation of local wave impact pressures caused by waves breaking directly onto a vertical breakwater or seawall. Minikin's formula for wave impact forces on vertical walls has been written:

$$
F_{h, \text { imp }}=\frac{101}{3} \cdot \frac{\rho \cdot g \cdot H_{D}^{2} \cdot d}{L_{D} \cdot D} \cdot(d+D)
$$

where $L_{D}$ is the design wave length, $D$ is the water depth at distance $L_{D}$ from the structure, $d$ is the water depth at the toe of the structure and $101=\pi \mathrm{g}$ is a debated conversion factor from American to S.I. units. More recent studies (Allsop et al. 1996c) demonstrated Minikin's formula as above to be qualitatively incorrect, since $F_{h, i m p}$ in Equation 2 decreases with increasing incident wave length $L_{D}$. as well as dimensionally inconsistent.

Goda (1974) developed new formulae for wave loads on vertical breakwaters based on a broad set of laboratory data and theoretical considerations (Goda 1967). Further work by Tanimoto et al. (1976), Takahashi et al. (1993) and Takahashi \& Hosoyamada (1994) extended the original method by Goda accounting for the effect of a berm, sloping top, wave breaking and incident wave angle. The prediction method by Goda (2000) represents the benchmark in the evolution of physically rational approaches to the assessment of wave loads at walls.

Blackmore \& Hewson (1984) carried out full scale measurements of wave impacts on a seawall in the South of West England using modern measuring and recording equipment. Comparison of new data-sets with previous experiments and prediction formulae proved that impact pressures in the field are generally lower then those measured during laboratory tests, mainly due to the high percentage of air entrained. Based on their observations, the authors developed the following prediction formula for average pressures under broken waves:

$$
p_{i}=\lambda \cdot \rho \cdot c_{s w}^{2} \cdot T
$$

where the aeration factor $\square \lambda$ has dimension of $\left[\mathrm{s}^{-1}\right]$ and accounts for the percentage of air entrainment, $\mathrm{T}$ is the wave period and $\mathrm{c}_{\mathrm{sw}}$ is the shallow water wave celerity. British Standard code of practice for marine structures (BS 6349) suggests evaluating wave impact pressures on sea-walls by means of Equation 3 using $\square \lambda=0.3 \mathrm{~s}^{-1}$ and $\lambda=0.5 \mathrm{~s}^{-1}$ respectively for rough/rocky foreshores or regular beaches.

Kirkgoz (1982, 1983, 1990, 1992, 1995) performed two-dimensional experiments using regular waves forced to break in front of a vertical wall by means of an approaching beach of variable slope. The author distinguished among early breaking, late breaking and perfect breaking and highlighted the relative importance of deep water wave steepness and beach slope on the maximum peak pressure and its position up the wall. Impact pressures and forces were found to vary significantly for small changes in water depth at the wall and to reduce drastically when an air pocket was entrapped between the wave front and the structure.

Within PROVERBS physical model tests at large- and small-scale were run in the Large Wave Flume (GWK) of Hannover, Germany and in the Deep Wave Flume (DWF) at HR Wallingford (HRW), Wallingford, UK. 
Analysis of large-scale tests led to results presented in Klammer et al. (1996) and Kortenhaus et al. (1994), respectively in terms of horizontal wave impact and uplift loading. The smaller-scale HR Wallingford tests are described in depth in Allsop et al. (1996a,b,c). The analysis of wave pressures and forces suggested the development of a new prediction method for wave impact forces on vertical breakwaters (Allsop et al. 1996a and Allsop \& Vicinanza 1996). The method is recommended in Oumeraci et al. (2001) for preliminary design and the British Standards (BS6349-1, 2000) and is expressed by:

$$
F_{h, i m p}=15 \cdot \rho \cdot g \cdot d^{2} \cdot\left(H_{s i} / d\right)^{3.134}
$$

where $H_{s i}$ is the (design) significant wave height at the toe of the wall and $d$ the water depth.

The advances in knowledge and prediction of wave loadings within PROVERBS led to a new procedure to assess wave impact loads on vertical breakwaters or sea walls. The new methodology is the first to quantitatively account for uncertainties and variability in the loading process and therefore represented a step forward towards the development of a more rational and reliable design tool. Moving from the identification of the main geometric and wave parameters, the method proceeds through 12 steps to evaluate wave forces (landward, up-lift and seaward), together with the corresponding impact rise time and pressure distribution up the wall. The new design methods are described in details in Allsop et al. (1999) and Oumeraci et al. (2001). In the methodology it was shown that the maximum horizontal impact force could be given by,

$$
F_{h, i m p}=F_{h, i m p}^{*} \cdot \rho \cdot g \cdot H_{b}^{2}
$$

where $H_{b}$ is the wave height at breaking (Oumeraci et al., 2001). The relative maximum wave force $F^{*}{ }_{h \text {;imp }}$ is assumed to obey a Generalised Extreme Value (GEV) distribution, given by:

$$
F_{h, i m p}^{*}=\frac{\theta}{\xi} \cdot\left(1-\xi \cdot \ln P_{\%}\right)+\mu
$$

where: $\mathrm{P}_{\%}$ is the probability of non-excedance of impact forces (suggested value for $\mathrm{P}$ is $90 \%$ ) and $\theta$, $\xi$ and $\mu$ are the scale, shape and location parameters of the GEV pdf, given as a function of the bed slopes.

An analytical approach to the prediction of impact pressures on walls was performed by Cooker \& Peregrine (1990a, 1990b, 1995) leading to the development of a mathematical model for upper-limit impact pressures based on the idea of "pressure-impulse". They solved a 2D boundary value problem for an idealised wave hitting a vertical wall resulting in an unexpectedly violent motion characterised by very high velocities, accelerations and therefore pressures. Influence of trapped air was further investigated by Topliss et al. (1992) and Peregrine \& Topliss (1994) assuming either a trapped air pocket or a bubbly mixture. More recently, the "wave bounce back" model developed by Wood et al. (2000) assumes that air trapped during wave impacts on seawalls will behave as an oscillating circular air bubble. The model has been found to compare favourably with experimental data from experiments carried out respectively at the University of Edinburgh and Adana (Wood et al. 2000; Kirkgoz \& Mamak 2004).

\section{Experimental setup, logging and analysis method}

Experimental investigations (Figure 1) were undertaken in the large wave flume (CIEM / LIM) at Universitat Politècnica de Catalunya in Barcelona, Spain. Access to the facility was via the EC FP5 Hydralab // project. The experiments were designed for two purposes : (a) the quantification of scale-effects on overtopping of vertical / battered walls, see results by Pearson et al. (2002) and, (b) the investigation of wave load characteristics on the wall. 
The LIM wave flume is $100 \mathrm{~m}$ long, $3 \mathrm{~m}$ wide along its full length, and has an operating depth of up to $4 \mathrm{~m}$ at the absorbing-wedge paddle. The experiments were conducted on a 1:13 concrete approach beach (see Figure 2). Each test used approximately 1000 irregular waves to a JONSWAP spectrum with $\gamma=3.3$. Five different water depths $d$ were used ranging from $0.53 \mathrm{~m}$ up to $1.28 \mathrm{~m}$. The test matrix of 39 different conditions is summarised in Table 1, together with information relative to the whole set of experiments; three structural configurations were tested, respectively: 10:1 steeply-battered wall (44 tests), vertical wall (18 tests) and vertical wall with wave-return wall (4 tests) for a total of 66 tests.
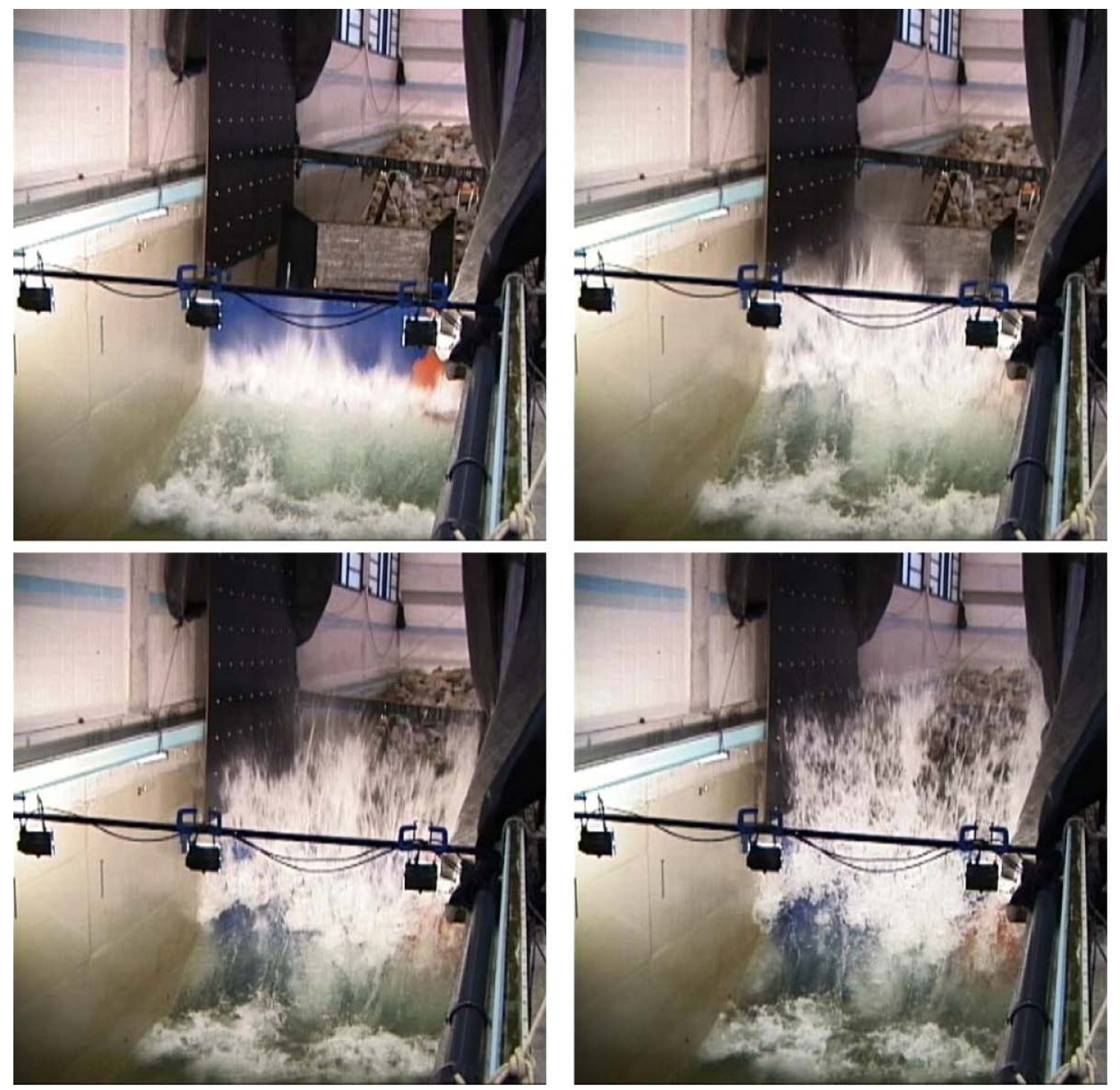

Figure 1

Large scale tests at LIM-UPC, snapshots $(\Delta t=0.12 \mathrm{~s})$ of a wave impact during physical model tests. 
Table 1 Summary of test conditions. Where two series are listed together (e.g. 1A \& 1B), the difference between the series was only in the additional freeboard

\begin{tabular}{|c|c|c|c|}
\hline $\begin{array}{c}\text { Test } \\
\text { Series }\end{array}$ & Configuration & $\begin{array}{c}\text { Nominal wave period } T_{m} \\
{[\mathrm{~s}]}\end{array}$ & $\begin{array}{c}\text { Nominal wave height } H_{m o} \\
{[\mathrm{~m}]}\end{array}$ \\
\hline \multirow[t]{5}{*}{$1 A \& 1 B$} & $R_{c}=1.16 \mathrm{~m} /$ & 2.56 & $0.48,0.45,0.37$ \\
\hline & $1.40 \mathrm{~m}$ & 3.12 & $0.60,0.56,0.39$ \\
\hline & $d=0.83 \mathrm{~m}$ & 3.29 & 0.67 \\
\hline & & 3.64 & 0.60 \\
\hline & & 1.98 & 0.25 \\
\hline \multirow[t]{5}{*}{$1 \mathrm{C}$} & $R_{C}=1.46 \mathrm{~m}$ & 1.98 & $0.25,0.22$ \\
\hline & $d=0.53 \mathrm{~m}$ & 2.56 & $0.48,0.45,0.37,0.23$ \\
\hline & & 3.12 & $0.63,0.60,0.56,0.39$ \\
\hline & & 3.29 & 0.67 \\
\hline & & 3.64 & 0.60 \\
\hline \multirow[t]{4}{*}{$1 \mathrm{D} \& 1 \mathrm{E}$} & $R_{C}=0.71 \mathrm{~m} /$ & 1.97 & $0.26,0.23$ \\
\hline & $0.95 \mathrm{~m}$ & 2.54 & $0.44,0.44,0.35,0.23$ \\
\hline & $d=1.28 \mathrm{~m}$ & 3.12 & $0.58,0.50,0.34$ \\
\hline & & 3.65 & 0.55 \\
\hline \multirow[t]{4}{*}{$1 F \& 11$} & $R_{c}=1.38 \mathrm{~m} /$ & 2.6 & 0.46 \\
\hline & $1.42 \mathrm{~m}$ & 3.15 & $0.59,0.51$ \\
\hline & $d=0.82 \mathrm{~m}$ & 3.4 & 0.59 \\
\hline & & 3.8 & 0.51 \\
\hline \multirow{3}{*}{$1 G \& 1 H$} & $R_{c}=0.98 \mathrm{~m} / 1.22$ & 3.15 & 0.59 \\
\hline & $\mathrm{m}$ & 3.4 & 0.59 \\
\hline & $d=1.22 \mathrm{~m}$ & 3.8 & 0.51 \\
\hline
\end{tabular}
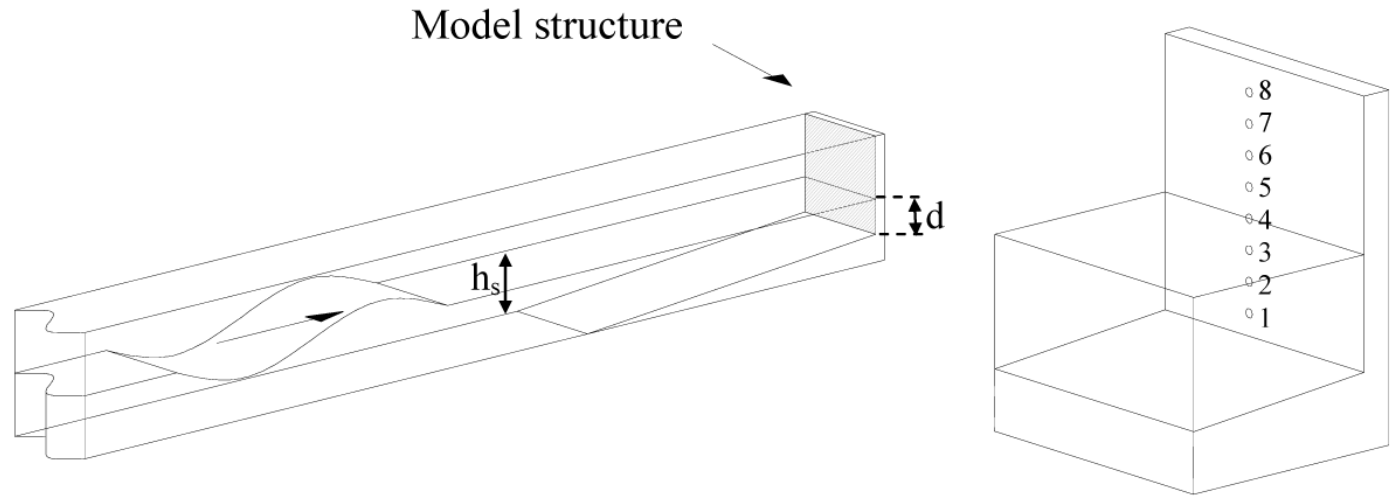

Figure 2 Experimental set-up: overall view with pressure transducers.

The pressure distribution on the wall was recorded by eight Druck pressure transducers connected to a data logging system. The transducers were fixed flush to the front face of the wall at a spacing of $0.2 \mathrm{~m}$ and were placed in a vertical array with the lower sensor located $0.1 \mathrm{~m}$ above the bottom of the wall. Transducers were logged at a frequency of $2000 \mathrm{~Hz}$. More detailed descriptions of the experimental setup are given in Pearson et al. (2002).

The total horizontal force $\left(F_{h}\right)$ and overturning moment $\left(M_{z}\right)$ on the seaward face of the wall were computed respectively as:

$$
\begin{aligned}
& F_{h}=\sum_{k} P_{k} \cdot \Delta z \\
& M_{z}=\sum_{k} P_{k} \cdot \Delta z \cdot z_{k}
\end{aligned}
$$


where $P_{k}$ is the pressure recorded by the $k^{\text {th }}$ pressure transducer, $\Delta z=0.20 \mathrm{~m}$ is the distance up the wall between two successive transducers, and $z_{k}$ is the absolute position of the $k^{\text {th }}$ transducer up the wall, including the top and the bottom sensors of the array. The array of pressure transducers reached well above the s.w.I. allowing the description of pressure distribution all over the wall, for consistency, measurements were extrapolated $0.1 \mathrm{~m}$ above the top sensor of the array. Visualisation of pressure distribution as measured from sensors up the wall (see §9) confirmed the array to cover the whole area of application of wave loads and Equations $7 \& 8$ to provide an efficient evaluation of global wave forces acting on the wall.

An example load-time history extracted from the signal recorded during test under nominal wave condition $\mathrm{H}_{\mathrm{m} 0}=0.48 \mathrm{~m}, \mathrm{~T}_{\mathrm{m}}=2.56 \mathrm{~s}, \mathrm{~d}=0.83 \mathrm{~m}, \mathrm{R}_{\mathrm{c}}=1.16 \mathrm{~m}$ is shown in Figure 3. The total (dimensionless) horizontal force (top) is shown together with the (dimensionless) lever arm of the overturning moment about the toe of the wall (bottom), evaluated for each time step as:

$$
z / d=\frac{M_{z}}{F_{h}} / d=\frac{\sum_{k} P_{k} \cdot \Delta z \cdot z_{k}}{\sum_{k} P_{k} \cdot \Delta z} / d
$$

An event was assumed to occur each time $F_{h}$ or $P_{k}$ up-crossed a threshold defined as, respectively:

$$
\begin{aligned}
& F_{\text {min }}=0.2 \cdot \rho g \cdot d \cdot H_{m 0} \\
& P_{\text {min }}=0.1 \cdot \rho g \cdot H_{m 0}
\end{aligned}
$$

For each pressure transducer location, the following parameters were extracted for each event from the signal recorded by each pressure transducer $\left(P_{k}\right.$, see Figure 4$)$ as well as for the overall force $\left(F_{h}\right)$ and moments $\left(M_{z}\right)$ according to the approach used in the PROVERBS project (McConnell \& Kortenhaus, 1997):

- the time $t_{0}$ corresponding to the beginning of the event (threshold up-crossing);

- the impact maximum $P_{k, i m p}, F_{\text {imp }}, M_{\text {imp }}$;

- its corresponding rise time $t_{r}\left(P_{k, i m p}\right), t_{r}\left(F_{i m p}\right), t_{r}\left(M_{i m p}\right)$;

- the maximum quasi-static load $P_{k, q s^{+}}, F_{q s^{+}}, M_{q s^{-}}$;

The following extra information has been extracted from each 1000 waves test:

- Horizontal forces: Fh,imp(1/250), $F_{h, q s+(1 / 250)}$

- Overturning moments: $M_{z, \operatorname{mp}(1 / 250),} M_{z, q s+(1 / 250)}$

where the subscript $(1 / 250)$ indicates that the corresponding parameter has been evaluated as the average of the highest four events in a (nominally) 1000-wave test.

The distinction between impulsive and quasi-static loads was based on the relative duration of the loading. In particular, "impacts" or "short-duration" loads are those that act on the structure for durations shorter or comparable with the resonance period of the structure. Conversely, "quasi-static" (also called slowly-varying or pulsating) loads are those that act on the structure for longer.

\section{Comparison with existing prediction methods}

Quasi-static horizontal (shoreward) forces as measured over the vertical face of the wall during the physical model tests are compared to predictions by existing methods on the left-hand side of Figure 5. Measured pulsating loads are compared with predictions by Hiroi (1920), Sainflou (1928) and Goda (1974). In the interests of completeness, methods by Hiroi and Sainflou are applied assuming a design wave $H_{D}$ 
respectively equal to $\mathrm{H}_{1 / 3}$ or to $H_{\max }=\min \left\{H_{1 / 250}=1.8 \cdot H_{1 / 3} ; H_{b}\right\}, \mathrm{H}_{\mathrm{b}}$ being the breaker height at distance $5 \mathrm{H}_{1 / 3}$ from the wall after Goda (2000).

Use of Goda's method gives the best predictions for the quasi-static forces over the whole range of parameters tested. Other methods (Hiroi with $\mathrm{H}_{\mathrm{D}}=\mathrm{H}_{1 / 3}$ and Sainflou with $\mathrm{H}_{\mathrm{D}}=\mathrm{H}_{\max }$ ) over-estimate quasistatic loads under "slightly breaking" conditions $\left(\mathrm{H}_{\mathrm{mo}} / \mathrm{d}<0.6\right)$ while under-estimating quasi-static loads when heavy breaking occurs $\left(H_{m 0} / d>0.6\right)$. Hiroi's method with $H_{D}=H_{\max }$ gives a generally conservative predictor. Sainflou's purely quasi-static method with $\mathrm{H}_{\mathrm{D}}=\mathrm{H}_{1 / 3}$ largely under-estimates quasi-static forces over the whole range of forces studied, with predictions diverging from measurements as $\mathrm{H}_{\mathrm{mo}} / \mathrm{d}$ increases. 

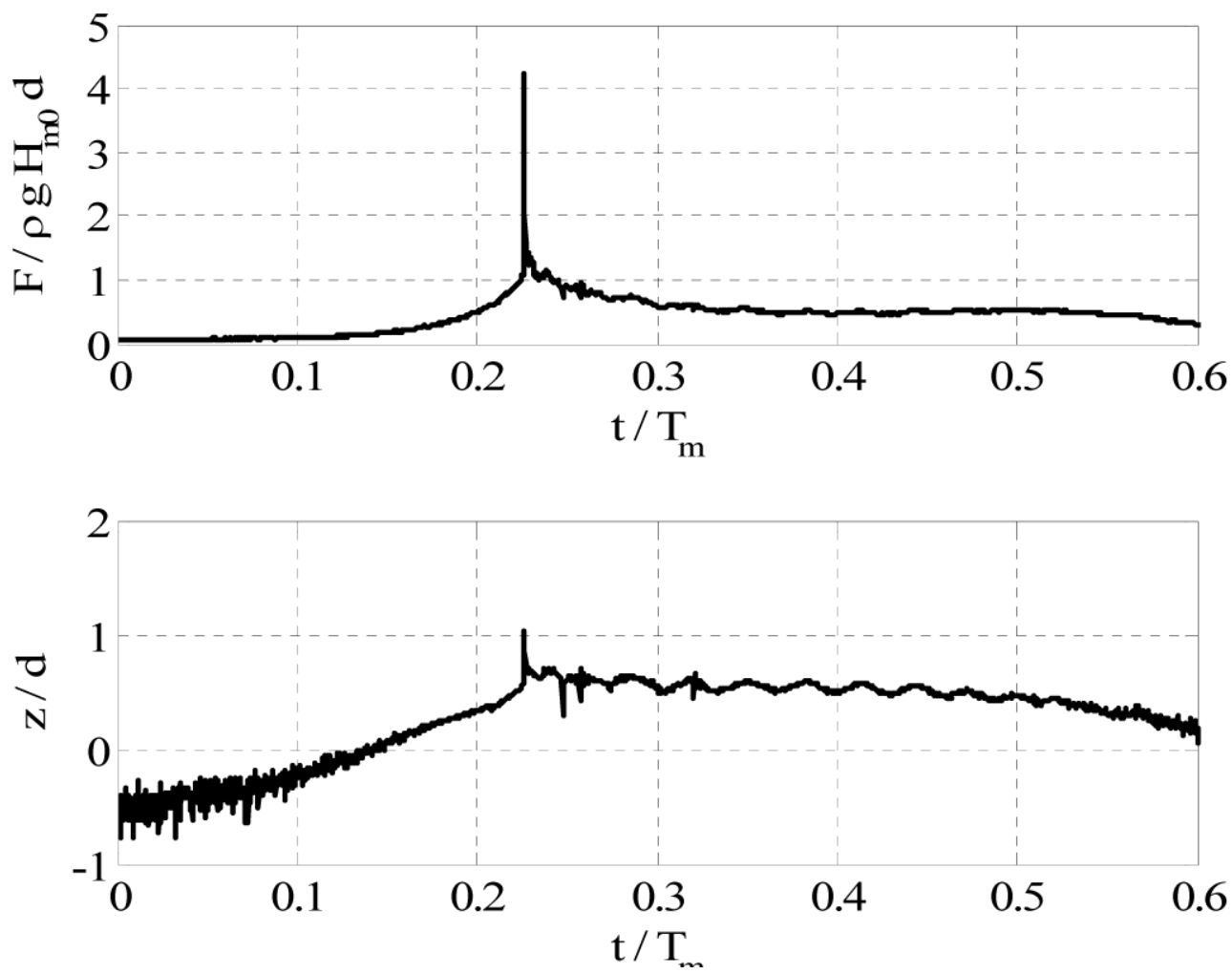

Figure 3 Example dimensionless time-history force recorded during the physical model tests (top), together with its corresponding variation in time of the level arm (z) normalised with respect to the water depth in front of the wall (d) (bottom).

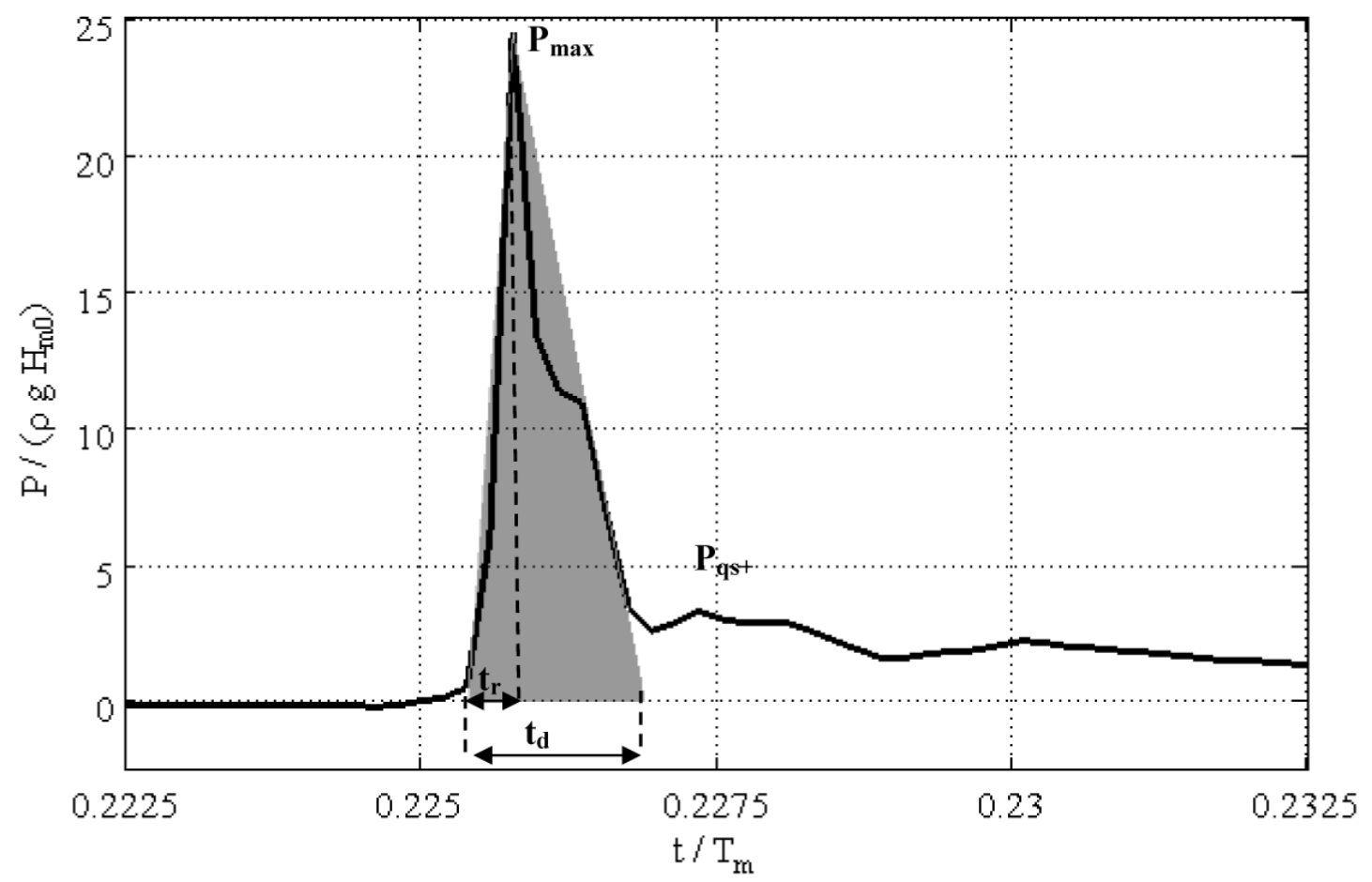

Figure $4 \quad$ Parameterisation of wave-impact time-history load recorded during physical model tests 


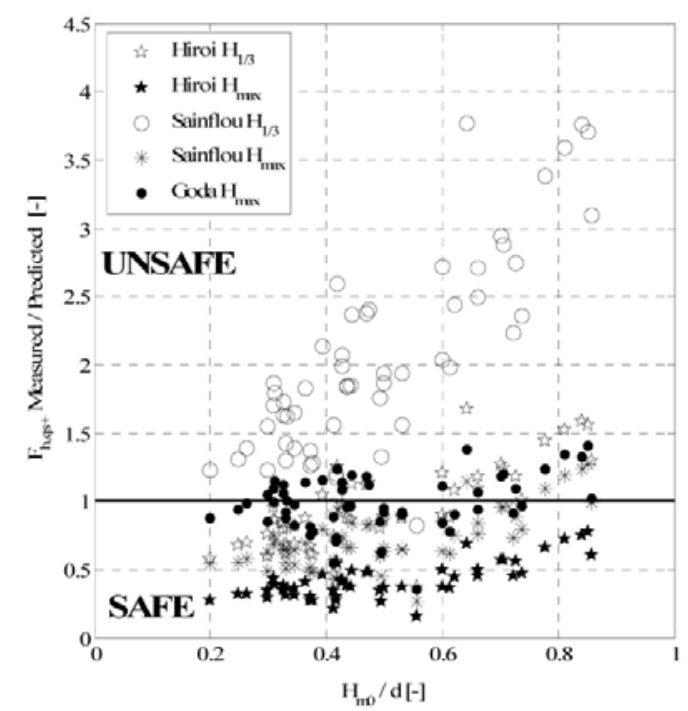

Figure $5 \quad$ Quasi static positive (shoreward) wave forces (at significant level 1/250) on the seaward face of the wall. Comparison between measurements and predictions by most established methods for different values of design wave at increasing $\mathrm{H}_{\mathrm{mo}}$ / d.

Impulsive forces over the vertical face of the wall were also compared with a range of methods, including those suggested in the Coastal Engineering Manual (Burcharth \& Hughes, 2002), British Standards BS6349, and the guidelines from PROVERBS. Measured wave impact loads are compared with predictions by Hiroi (1920), Minikin (1963), Goda (1974), Takahashi et al. (1994), Blackmore \& Hewson (1984), Allsop \& Vicinanza (1996), and Oumeraci et al. (2001) in Figure 6.

The scatter is large for all the prediction methods used over the range of measured forces (note change in scale from Figure 5 to 6). Points lying above an ordinate value of 1.0 represent unsafe predictions. Within the range of conditions tested, use of existing prediction methods is generally 

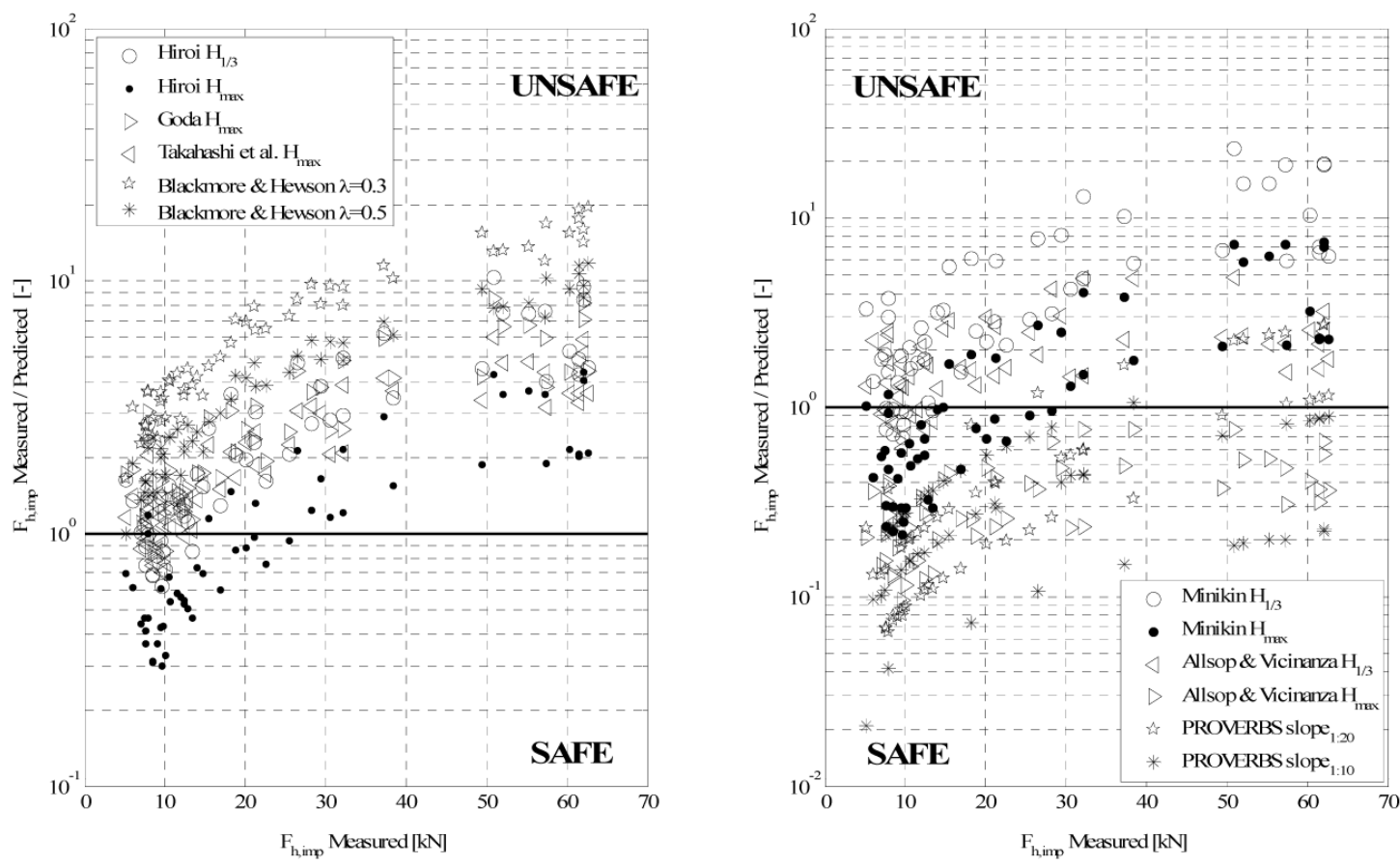

Figure $6 \quad$ Impact wave forces (at significant level 1/250) on the seaward face of the wall. Comparison between measurements and predictions by most established methods

safe for relatively small impacts but might lead to significant under-estimation of the severest loadings.

Blackmore \& Hewson's method was derived using field measurements under mostly broken (thus highlyaerated) wave attack and its application is not rigorous in this context - confirmed on the left-hand side of Figure 6, showing that Equation 3 under-estimates measured wave impacts.

As expected, methods by Goda (1974) and Takahashi et al. (1994) significantly underestimate measured impulsive loads not surprising since neither method were developed to predict short-lasting impact forces, as these were assumed to be damped by the dynamic response of the caisson.

The PROVERBS prediction method (right-hand side of Fig. 6) gives a generally safe prediction, but a relatively large scatter in predictions is noticeable when the method is entered with different values of the bed slope. Example calculations in Fig 6 have been derived entering Equation 6 with values of $\theta, \xi$ and $\mu$ corresponding to bed slopes equal to 1:20 and 1:10. Assuming a bed slope of 1:20 gives the best estimate of measured values, while using coefficients for bed slope of 1:10 results in a large overestimation of the loads.

Using Allsop \& Vicinanza's method (Equation 4), measured impacts fall between predictions arrived at by assuming respectively $\mathrm{H}_{\mathrm{D}}=\mathrm{H}_{1 / 3}$ and $\mathrm{H}_{\max }$, with the two sets of predictions providing a (rather wide) lower and upper limit of the loading. Use of Hiroi's and Minikin's methods (with $H_{D}=H_{\max }$ ) also gives a relatively good estimate of lowest impacts but significantly underestimates most severe impacts. Use of such methods assuming $\mathrm{H}_{\mathrm{D}}=\mathrm{H}_{1 / 3}$ is generally unsafe.

\section{Relative importance of tested parameters}

All tests at LIM / UPC Barcelona were conducted under impulsive or nearly-impulsive conditions. In order to identify parameters to which wave loading of vertical structures subject to breaking wave attack were most 
sensitive, the relative effects of parameters $\left(H_{m 0}, T_{m}, d\right)$ on pulsating (both shoreward, $F_{h, q s^{+}}$and seaward $F_{h, q s}$ ) and impulsive $\left(F_{h, \text { imp }}\right)$ wave forces and corresponding overturning moments (respectively $M_{z, q s^{+}}$, $M_{z, q q_{-}}$and $M_{z, \text { imp }}$ ) was investigated. The analysis was carried out to explore further the physical basis of the loading process with the final aim of developing a more rational prediction tool, which would be refined and validated by observations and data of previous research.

Relative importance of incident significant wave height $\left(H_{m 0}\right)$ on horizontal wave forces and moments on the wall is shown in Figure 7 for different values of water depth at the structure $d$. As expected, both $F_{h}$ and $M_{z}$ increase with increasing $H_{m 0}$.

The relative importance of incident wavelength at the toe of the structure $L\left(h_{S}\right)$ for $T=T_{m}$ on horizontal wave force $\left(F_{h}\right)$ and overturning moment $\left(M_{z}\right)$ on the wall is shown in Figure 8 for different values of water depth at the structure $d$. Both $F_{h}$ and $M_{z}$ increase with increasing $L\left(h_{S}\right)$. This is as expected, as increasing wavelength also means increasing wave celerity, which results in increased shoreward kinetic energy and momentum.

Dependencies of wave forces and moments on $H_{m 0} / d$ and $H_{m 0} / h_{s}$ are shown respectively in Figures 9 and 10. As expected, shoreward wave loads increase for increasing $\mathrm{H}_{\mathrm{m} 0} / \mathrm{d}$ and $H_{m 0} / h_{s}$. 

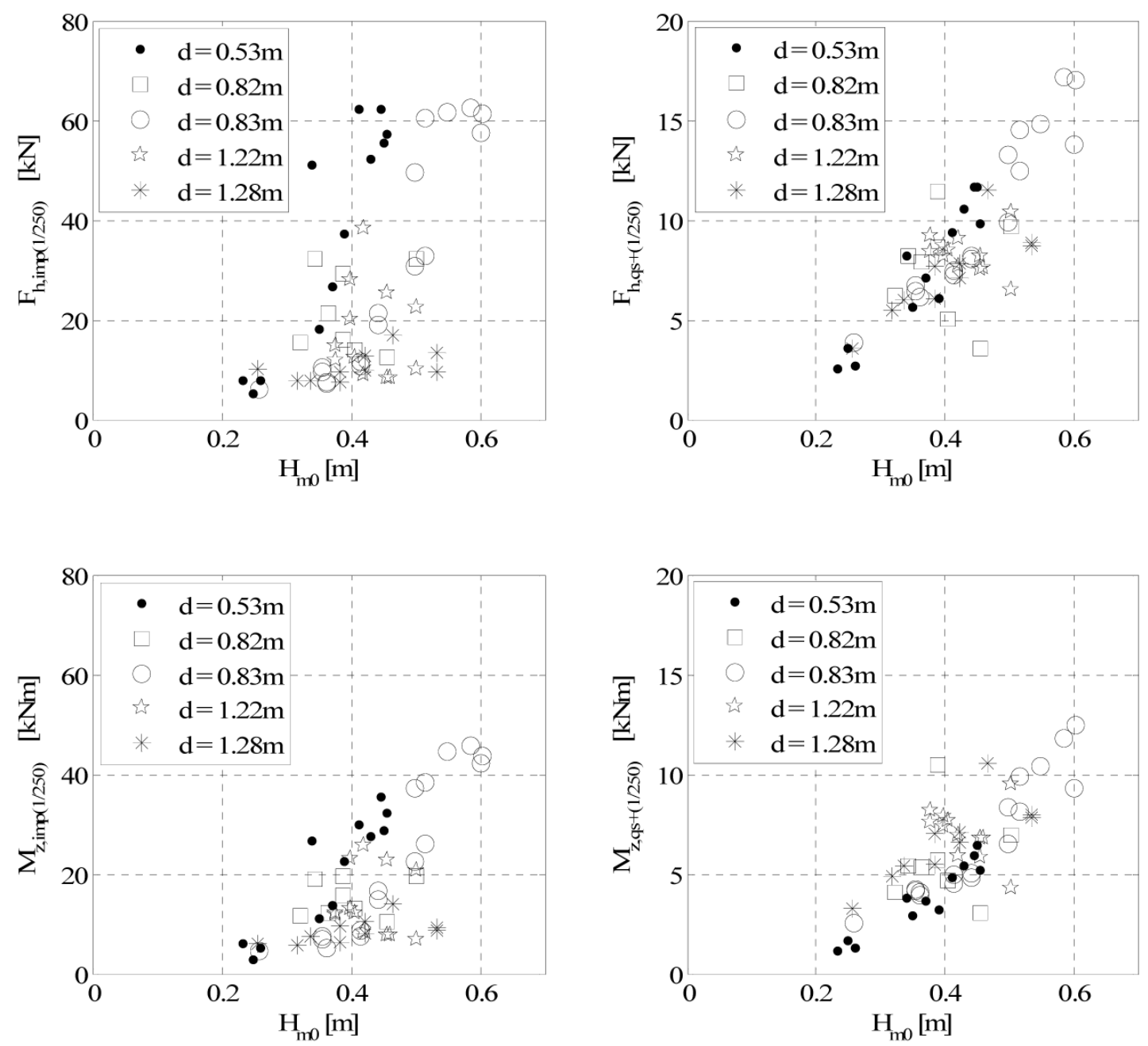

Figure $7 \quad$ Relative importance of incident significant wave height Hm0 on positive (shoreward) impulsive (left) and quasi static (right) forces Fh (top) and overturning moments Mz (bottom) at significance level 1/250. 

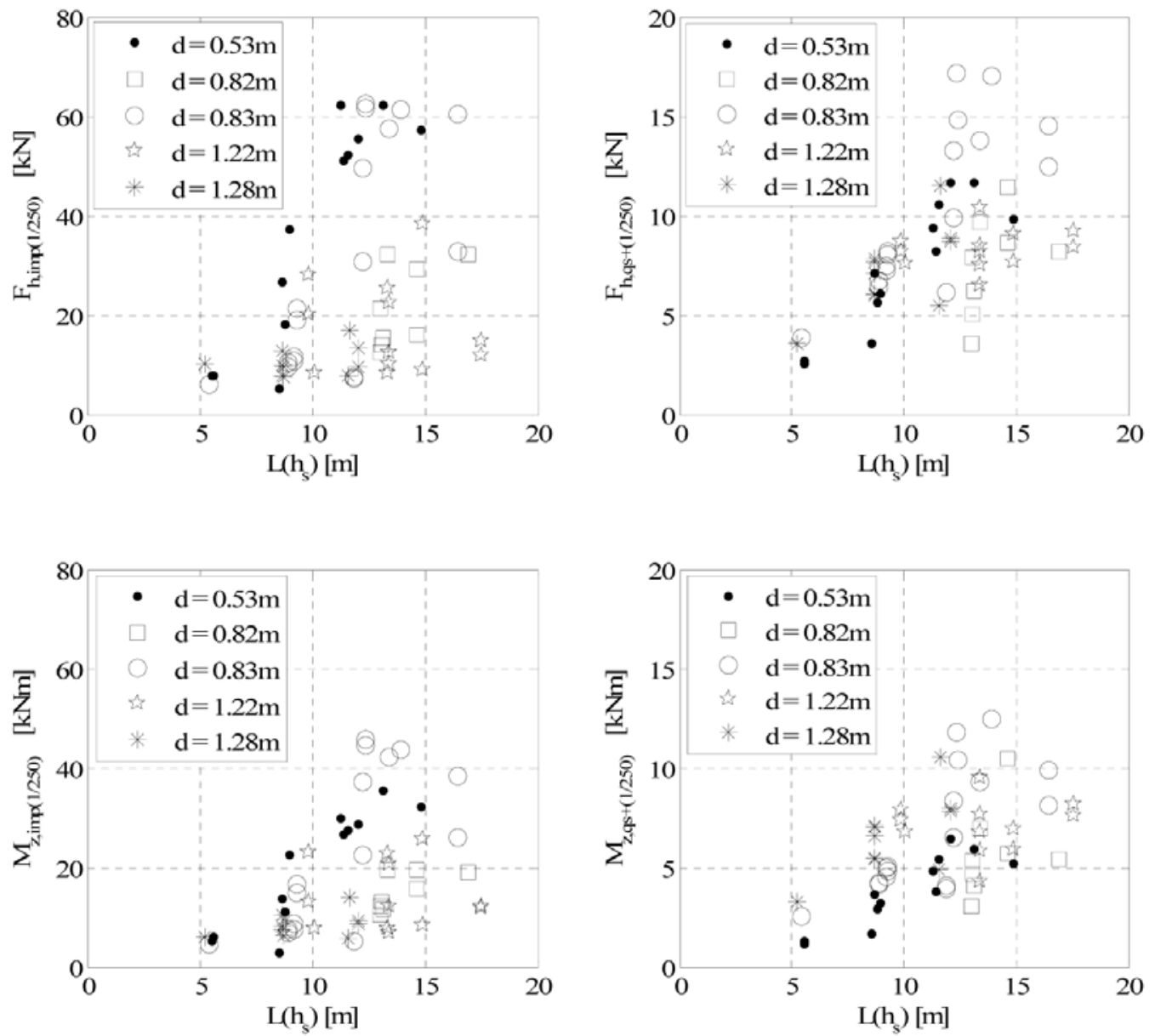

Figure $8 \quad$ Relative importance of wave length at the toe of the structure $L(h s)$ (for $T=T m$ ) on positive (shoreward) impulsive (left) and quasi static (right) forces Fh (top) and overturning moments Mz (bottom) at significance level 1/250. 

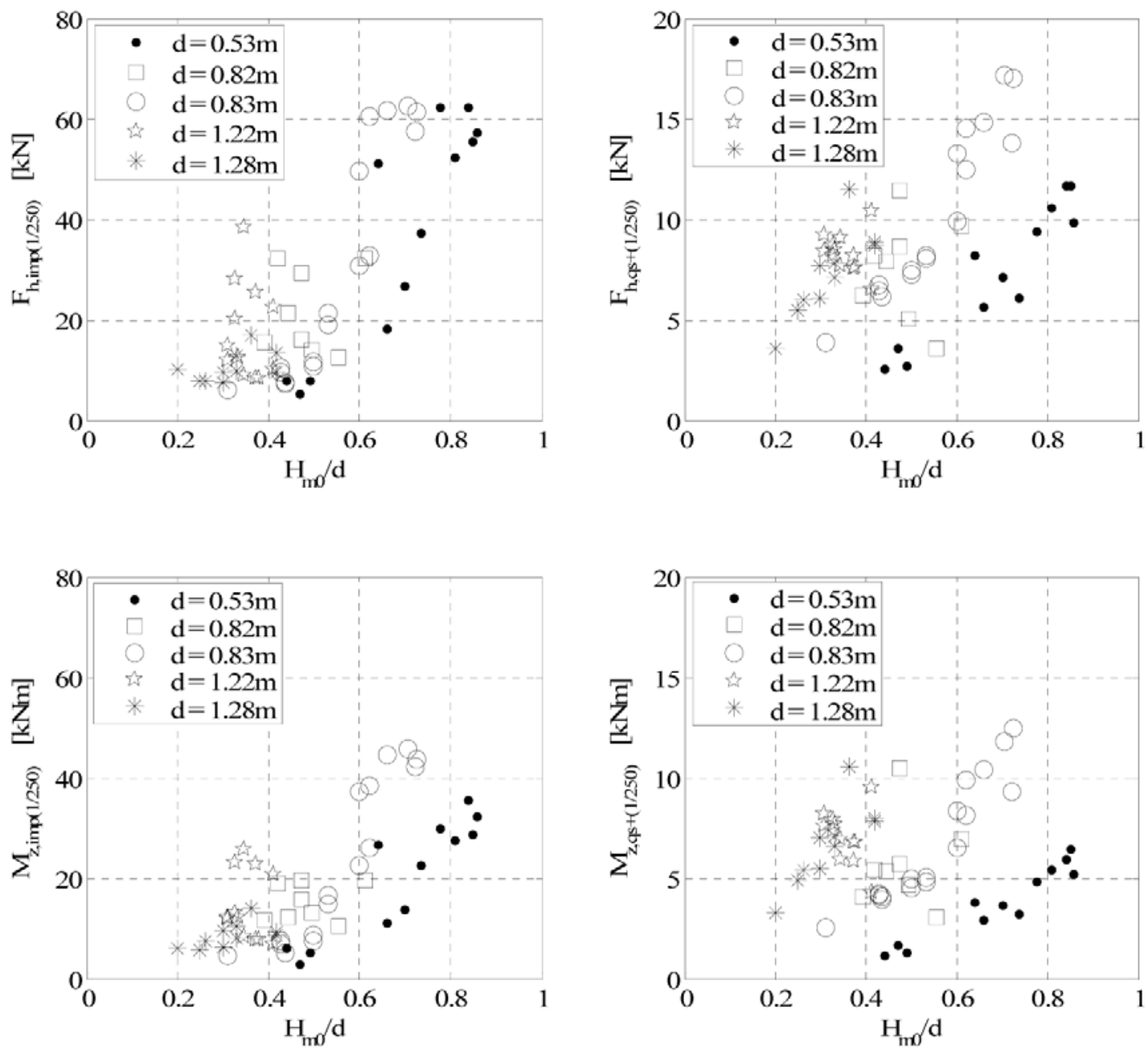

Figure $9 \quad$ Relative importance of relative incident significant wave height Hm0/d on positive (shoreward) impulsive (left) and quasi static (right) forces Fh (top) and overturning moments Mz (bottom) at significance level 1/250. 

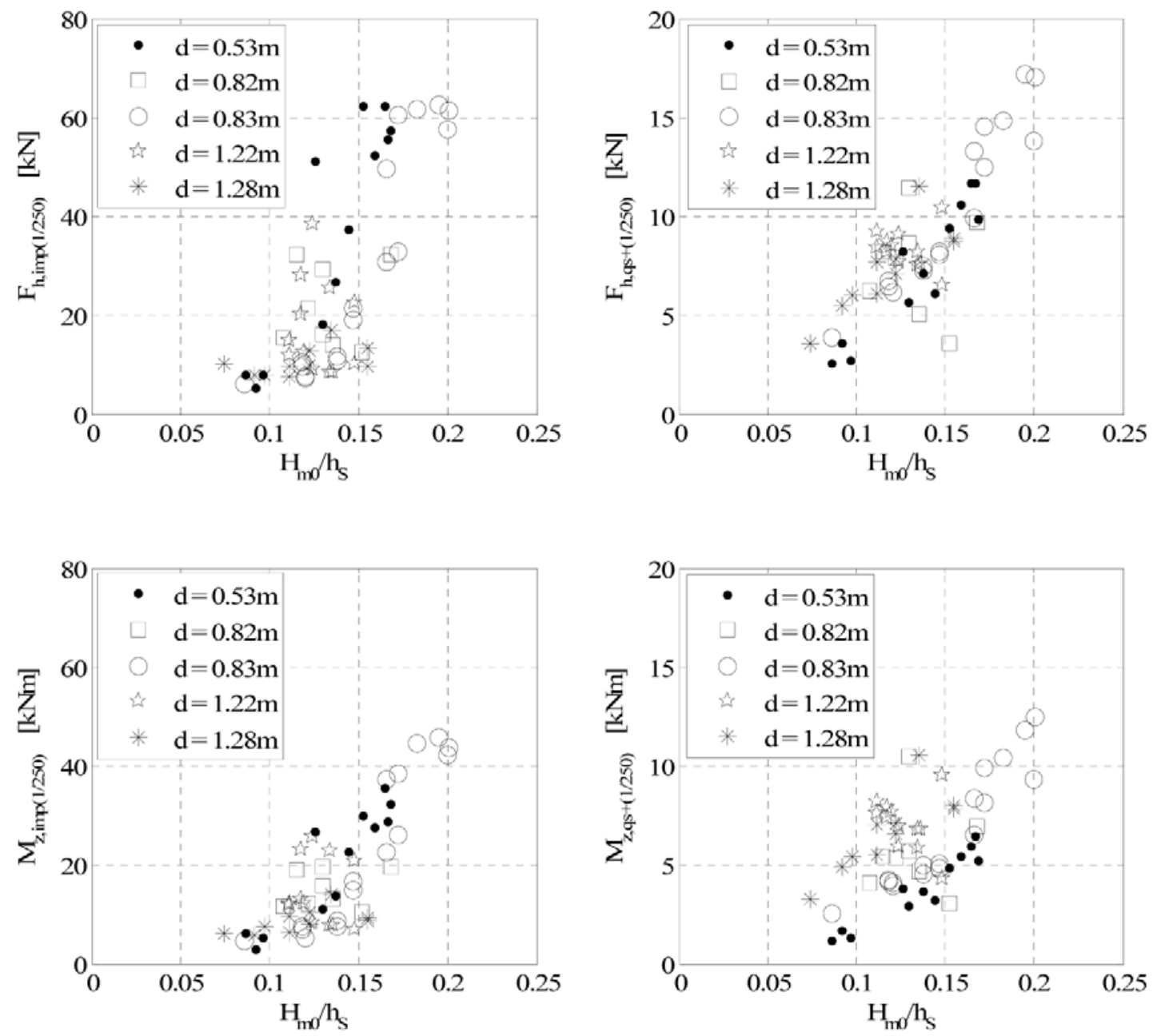

Figure 10 Relative importance of relative incident significant wave height $\mathrm{HmO} / \mathrm{hs}$ on positive (shoreward) impulsive (left) and quasi static (right) forces Fh (top) and overturning moments Mz (bottom) at significance level 1/250. 

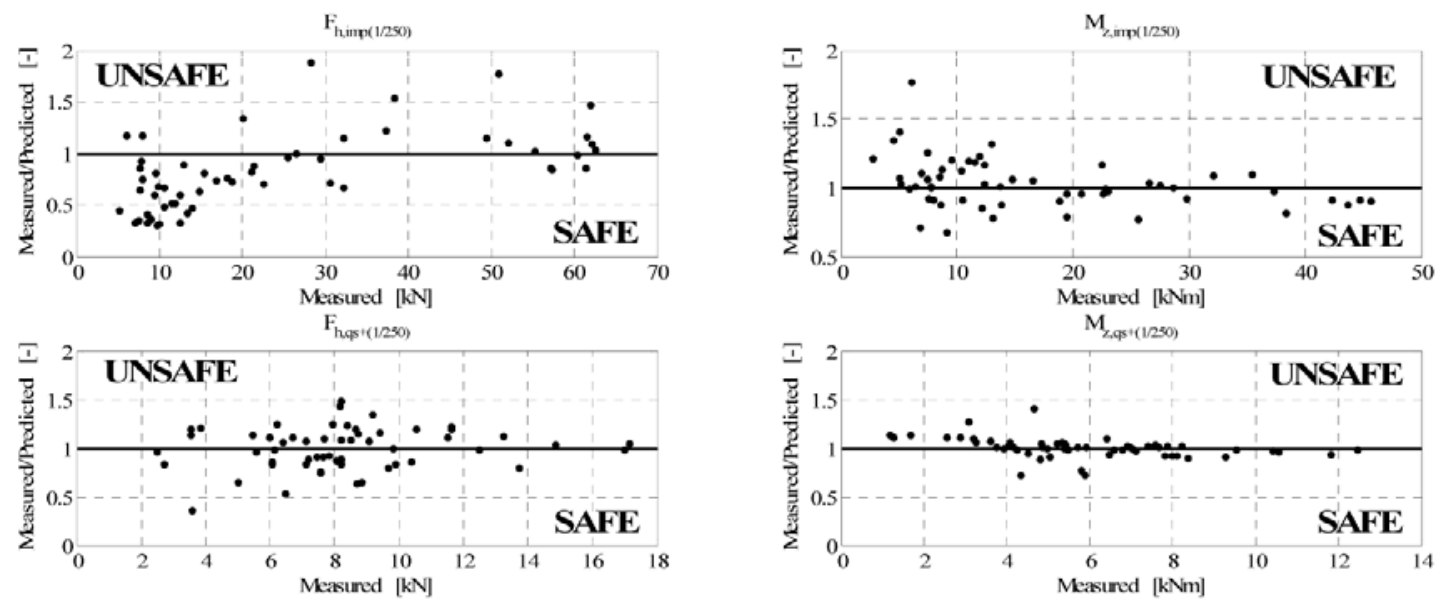

Figure $11 \quad$ Comparison of measurements from large-scale tests at LIM with prediction by present set of formulae (Equations 12-17). From top to bottom: impact forces (left) and overturning moments (right), positive (shoreward) quasi-static forces (left) and overturning moments (right).

\section{New prediction formulae for impacting wave loads}

The relative importance of the incident wave height and wavelength on horizontal wave impacts has been discussed. It is proposed that the total impacting horizontal (shoreward) force in the seaward direction of a vertical structure be given by:

$$
F_{h, i m p(1 / 250)}=\rho g \cdot H_{m 0} \cdot L\left(h_{s}\right) \cdot\left(1-\frac{\left|h_{b}-d\right|}{d}\right)
$$

where $L\left(h_{s}\right)$ is the wavelength at the toe of the structure, for $T=T_{m}$ and $\alpha$ is an empirical coefficient taken as 1.65. Equation 12 is valid for $0.2 \mathrm{~m}<\mathrm{H}_{\mathrm{m} 0}<0.7 \mathrm{~m}, 0.5 \mathrm{~m}<\mathrm{d}<1.3 \mathrm{~m}$, and $2.0 \mathrm{~s}<T_{m}<3.7 \mathrm{~s}$.

The term in brackets in Equation 12 represents the difference between the water depth $d$ at the structure and the water depth at breaking $\left(h_{b}\right)$ and to a certain degree accounts for the severity of the breaking at the structure. Here, $h_{b}$ is evaluated by the Miche (1944) breaking criteria assuming $H_{b}=H_{m o}$ :

$$
h_{b}=\frac{1}{k} \operatorname{arctanh}\left[\frac{H_{m 0}}{0.14 \cdot L\left(h_{s}\right)}\right]
$$

where $k=2 \pi / L\left(h_{s}\right)$.

Predictions by Equation 12 compare well with wave impact forces as measured during the physical model tests, as shown on the left-hand side of top panel in Figure 11. Since the structural configuration used in the experiment had no porous berm (the foreshore consisting of an impermeable slope) the reflection coefficient $C_{r}$ in Equation 12 has been taken equal to 1 (full reflection) to get predictions in Figure 11. Overall $R^{2}=0.41$ for this distribution.

The goodness of fit to the Big-VOWS data by predictions using Equation 12 has been compared to those by existing methods in $\S 2$ in terms of: bias, standard deviation $\sigma$ and the summed square of residuals (or sum of squares due to error, SSE), defined as: 


$$
S S E=\sum_{i=1}^{N} \frac{\left(y_{i}-\hat{y}_{i}\right)^{2}}{\sigma^{2}}
$$

where $\mathrm{N}$ is the number of test, $y_{i}$ is the measured force (at $1 / 250$ level), $\hat{y}_{i}$ the prediction and $\sigma^{2}$ is the total variance of the data. Results are summarised in Table 2, confirming improvement in predictions over existing methods.

Table 2 Impact horizontal (shoreward) forces: comparison between measurements under Big-VOWS and predictions by existing methods (\$2) and present formula (Equation 12).

\begin{tabular}{|c|c|c|c|c|c|}
\hline Author & Foreshore & Design wave height & Bias & $\sigma$ & SSE \\
\hline Goda (1974) & & $\mathrm{H}_{\max }$ & -0.93 & 1.91 & 89 \\
\hline Goda (2000) - Takahashi et al. (1994) & & $\mathrm{H}_{\max }$ & -0.63 & 1.32 & 77 \\
\hline Hiroi (1920) & & $\mathrm{H}_{1 / 3}$ & -0.96 & 2.17 & 92 \\
\hline Hiroi (1920) & & $\mathrm{H}_{\max }$ & -0.15 & 0.80 & 60 \\
\hline Minikin (1963) & & $\mathrm{H}_{1 / 3}$ & -2.09 & 4.85 & 112 \\
\hline Minikin (1963) & & $\mathrm{H}_{\max }$ & -0.38 & 1.50 & 89 \\
\hline Blackmore \& Houson (1984) & Rocky ( $\quad \lambda=0.3$ ) & $\mathrm{H}_{\max }$ & -3.12 & 5.66 & 126 \\
\hline Blackmore \& Houson (1984) & Beaches $(\lambda=0.5)$ & $\mathrm{H}_{\max }$ & -1.67 & 3.18 & 111 \\
\hline PROVERBS (2001) & Slope 1:10 & $\mathrm{H}_{\mathrm{b}}$ & 0.33 & 0.50 & 1723 \\
\hline PROVERBS (2001) & Slope (Any) & $\mathrm{H}_{\mathrm{b}}$ & 0.20 & 0.60 & 670 \\
\hline PROVERBS (2001) & Slope $1: 20$ & $\mathrm{H}_{\mathrm{b}}$ & 0.22 & 0.58 & 779 \\
\hline Allsop \& Vicinanza (1996) & & $\mathrm{H}_{1 / 3}$ & -0.48 & 0.98 & 47 \\
\hline Allsop \& Vicinanza (1996) & & $\mathrm{H}_{\max }$ & 0.33 & 0.49 & 542 \\
\hline Present Formula (Equation 12) & & $\mathrm{H}_{\mathrm{m} 0}$ & 0.09 & 0.28 & 18 \\
\hline
\end{tabular}

The following expression is suggested for the design overturning moment corresponding to the horizontal impact force given by Equation 12:

$$
\begin{aligned}
M_{z, i m p(1 / 250)}= & F_{h, i m p(1 / 250)} \cdot \\
& d \cdot\left(0.78 \cdot \frac{H_{m 0}}{d}+0.34\right)
\end{aligned}
$$

valid for $0.2 \mathrm{~m}<H_{m 0}<0.7 \mathrm{~m}$ and $0.5 \mathrm{~m}<d<1.3 \mathrm{~m}$.

Overturning moments $M_{z ; \text { imp }}$ due to impacts pressures $F_{h, \text { imp }}$ derived from Equation 15 are plotted on the righthand side of the top panel of Figure 11, $\mathrm{R}^{2}=.0 .74$

\section{New prediction formulae for quasi-static part of breaking wave loads}

This section compares results and derives formulae for the quasi-static component of the horizontal (shoreward) forces and corresponding overturning moment. It should be borne in mind that quasi-static loads referred to in this section do not correspond to the pulsating loads exerted by standing waves, for which well established prediction methods exists (Goda, 2000 and Sainflou, 1928) but rather to the slowly-varying load applied by breaking waves. The total quasi-static horizontal (shoreward) force on the seaward face of the wall can be expressed as:

$$
F_{h, q s+(1 / 250)}=\alpha \cdot \rho g \cdot H_{m 0}^{2}
$$


where $\mathrm{H}_{\mathrm{m} 0}$ is the significant wave height at the toe of the structure and $\alpha=4.76$ is an empirical coefficient fitted to the new experimental data.

Comparison of quasi-static horizontal (shoreward) forces as measured during the physical model tests are compared to predictions by Equation 16 on the left-hand side of the central panel of Figure 11, for this fit $\mathrm{R}^{2}=$ 0.72 .

As expected, both water depth at the structure $(d)$ and incident significant wave height $\left(H_{m 0}\right)$ influence the lever arm of the horizontal force $F_{h}$. Their relative importance has been taken into account in the following expression for the design overturning moment corresponding to the horizontal pulsating force given by Equation 16:

$$
\begin{aligned}
M_{z, q s+(1 / 250)}= & F_{h, q s+(1 / 250)} \cdot \\
& d \cdot\left(0.43 \cdot \frac{H_{m 0}}{d}+0.59\right)
\end{aligned}
$$

Overturning moments due to pulsating shoreward pressures are compared to predictions (using Equation 17) on the right-hand side of the central panel of Figure 11. For this distribution $\mathrm{R}^{2}=0.74$.

The bias, standard deviation and sums of squares due to error using Equations 16 are compared in Table 3 to those by the predictions methods reviewed in $\S 2$. Goda's method is confirmed to give the best prediction of shoreward pulsating loads, among existing prediction methods, with Equation 16 representing a much simpler but nevertheless accurate alternative.

\section{Comparison with other data sets}

Within the framework of PROVERBS project, an extended set of physical model

tests at large and small scale were run respectively in the Large Wave Flume (GWK) of Hannover, Germany and in the Deep Wave Flume (DWF) at Hydraulic Research Wallingford (HRW), UK.

\subsection{The GWK data set}

The GWK is $320 \mathrm{~m}$ long, $5 \mathrm{~m}$ wide and $7 \mathrm{~m}$ deep and is equipped with a wave generator for both regular and random waves. Waves up to $2 \mathrm{~m}$ high and $9.4 \mathrm{~s}$ period were used in the experiments. A $6 \mathrm{~m}$-high vertical wall was located at the top of an inclined sea-bed (slope 1:20) and instrumented by mean of 28 pressure transducers, sampling at $11 \mathrm{kHz}$. The water depth at the paddle was $3.0 \mathrm{~m}$, but reduced up to $1.6 \mathrm{~m}$ at the wall (Oumeraci et al. 1992). Relative importance of sampling rate on the accuracy of impact loads measurements was also discussed (see Schmidt et al. 1992 and Oumeraci et al. 1994), with a reduction in the maximum impact pressure of almost $20 \%$ when a sampling rate lower than $1 \mathrm{kHz}$ was used. Force maxima were found (as expected) to be less sensitive to the sampling frequency.

\subsection{The HRW data set}

The Deep Wave Flume (DWF) at HRW was $52 \mathrm{~m}$ long with water depth at the paddle between $0.8 \mathrm{~m}$ and $1.75 \mathrm{~m}$, and divided into three parallel channels: two "absorbing" side-channels, each $0.9 \mathrm{~m}$ wide, $42 \mathrm{~m}$ long and one central "test" channel $1.2 \mathrm{~m}$ wide, $52 \mathrm{~m}$ long. For these experiments, from deep water near the paddle, the seabed sloped initially at 1:10 with a gradual transition to a more gentle 1:50 slope, and terminated in a $5 \mathrm{~m}$ flat section where the model was placed. Eleven structures were tested, including a 
simple vertical wall and composite walls with different mound geometries. Pressure transducers were installed at 8 positions on the front face of the caisson, 4 on the underside and 4 just below the surface of the rubble mound, all the transducers were logged at $400 \mathrm{~Hz}$. Random sea state were used for all the tests, generated according to Jonswap spectra. The tests are described in depth in Allsop et al. (1996c).

\subsection{Scale effects}

For practical use, data from physical model tests need back-scaling to prototype scale.

It is widely recognised that use of Froude similarity for back-scaling wave impact recorded at different scales may lead to over-estimation of impact maxima. In the following, wave impact maxima have been scaled using the model proposed by Cuomo and Allsop (2008), based on the "compression model law" originally proposed by Mitsuyasu (1966) and successively extended by Lundgren (1969) and Takahashi et al. (1985).

Let us introduce the Bagnold number as the relative peak pressure (after Takahashi et al., 1985):

$$
B g=\frac{\rho \cdot k_{B} \cdot u_{0}^{2}}{P_{0} \cdot D_{B}}
$$

where $u_{0}$ is the wave characteristic velocity, $P_{0}$ the atmospheric pressure, $k_{B}$ is the effective water mass and $D_{B}$ is the thickness of the air layer compressed at impact. Parameters $k_{B}, u_{0}$ and $D_{B}$ depend on the geometrical characteristics of the flow at impact.

Takahashi et al (1985) solved the equation of motion under the assumption of adiabatic compression of air at impact, for the case and no air leakage, deriving the following functional relationship:

$$
B g=5 \cdot\left(\frac{P_{\max }}{P_{0}}\right)^{2 / 7}+2 \cdot\left(\frac{P_{\max }}{P_{0}}\right)^{-5 / 7}-7
$$

From Equation 19 above it is evident that the ratio $P_{\max } / P_{0}$ depends on the Bagnold number; since the reference (atmospheric) pressure $P_{0}$ cannot be scaled in the model, measurements need to be corrected (multiplied) by a factor $\lambda_{\mathrm{s}}$ given by:

$$
\lambda_{s}=\frac{\left(P_{\max , P}-P_{0}\right) / P_{0}}{\left(P_{\max , M}-P_{0}\right) / P_{0}}
$$




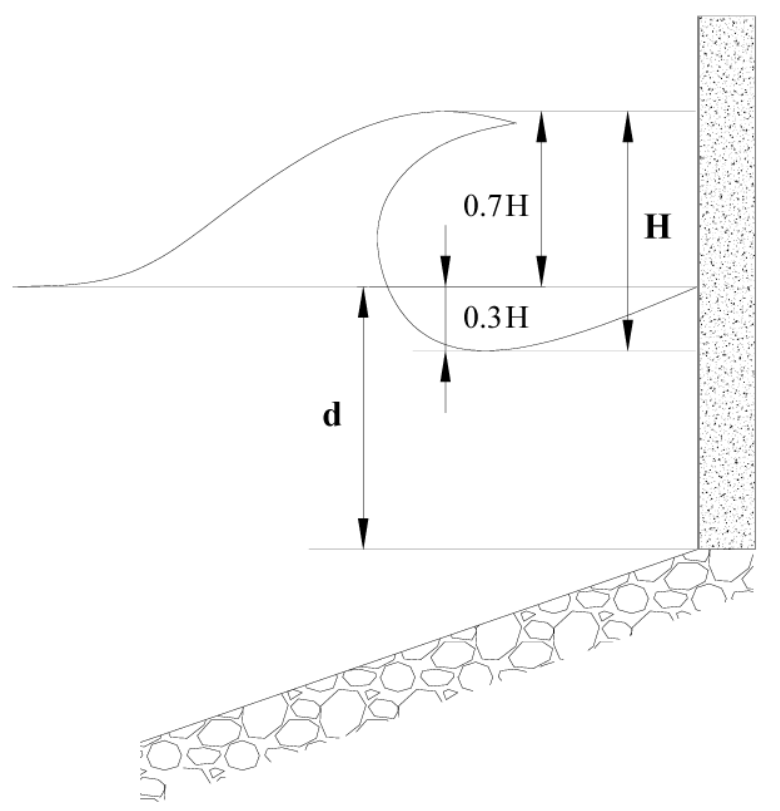

Figure $12 \quad$ Idealised representation of wave profile at incipient breaking with definition of most informative geometrical parameters.

In order to compare prediction from measurement at different scales, data from GWK and HRW were normalised to the LIM model scale, i.e to an averaged Bagnold number $B g_{P}=0.06$. Pressures from each experiment in the GWK and HRW data sets were scaled according to their corresponding Bagnold numbers (averaged Bagnold numbers were equal to 0.08 and 0.03 respectively; left-hand side of Figure 13) leading to (averaged) scale corrections of about 1.18 and 0.66 respectively for the large scale tests at GWK and the small scale tests at HRW (right-hand side of Figure 13).
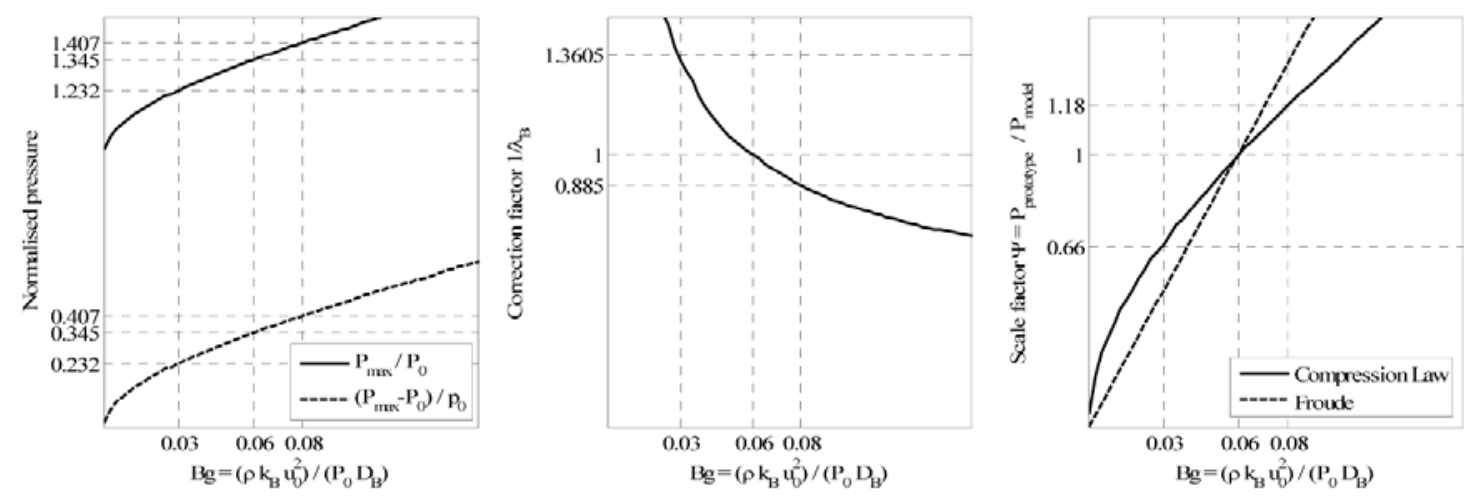

Figure 13 "Compression law" in the range of Bagnold numbers corresponding to physical model tests at large (GWK) and small (HRW) scale under PROVERBS.

The above procedure can be used to scale forces predicted by Equation 12 to prototype scale. To facilitate back-scaling from model to prototype scale, correction factors have been derived for Bagnold numbers between 0 and 1. Results are given in Figure 14. Graphs in Figure 14 can be used for back-scaling predictions by Equation 12 to prototype scale. For example, let the model to prototype ratio be 1:10; to backscale results from physical model tests at LIM (average Bagnold number $=0.06$ ) to prototype scale (Bagnold number $=0.6$ ) requires multiplying prediction by Equation 12 by a "corrected" scaling factor equal to 4.75 (right-hand side of Figure 14) instead of 10 (using Froude). 

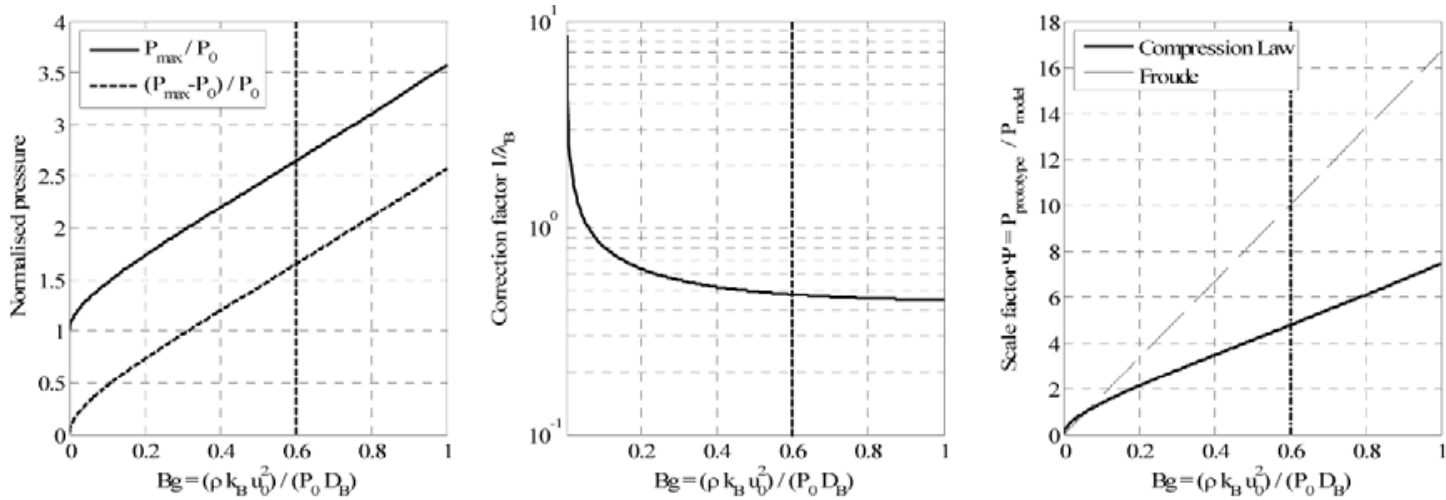

Figure $14 \quad$ "Compression law" in the range of Bagnold numbers ranging between 0 and 1 for use in back-scaling results from physical model test to prototype scale.

Since tests carried out during PROVERBS were performed using more absorbing structures, Equation 12 had to be extended to include effect of the reflection coefficient of the structure, leading to:

$$
F_{h, i m p(1 / 250)}=C_{r}^{\alpha} \cdot \rho g \cdot H_{m 0} \cdot L\left(h_{s}\right) \cdot\left(1-\frac{\left|h_{b}-d\right|}{d}\right)
$$

where $C_{r}$ is the reflection coefficient of the structure. Equation 23 reduces to Equation 12 when the structure is fully reflective, as in the case of the new tests series.

In presence of a significant permeable mound, the effect of heavy wave breaking on $C_{r}$ can be accounted for by assuming:

$\mathrm{C}_{\mathrm{r}}=0.7-0.9$ for little breaking and low mounds

$C_{r}=0.5-0.7$ for heavy breaking and/or large mounds

Wave transmission due to overtopping might also reduce impact forces. Analysis of laboratory data by Allsop et al. (1994) suggests simple limits for plain vertical walls where some overtopping may reduce the reflections:

$$
\begin{array}{ll}
\mathrm{C}_{\mathrm{r}}=0.9 & \text { for } 1.0<\mathrm{R}_{\mathrm{c}} / \mathrm{H}_{\mathrm{s}}<3.0 \\
\mathrm{C}_{\mathrm{r}}=0.8+0.1 \mathrm{R}_{\mathrm{c}} / \mathrm{H}_{\mathrm{s}} & \text { for } 0.4<\mathrm{R}_{\mathrm{c}} / \mathrm{H}_{\mathrm{s}}<1.0
\end{array}
$$

To compare measurement from physical model tests at different scales, we applied the procedure described in section 8.3 to homogenize data to a single scale. Results are shown in Figure 15, with the scales measured force compared with prediction by Equation 21. When compared to scatter in prediction by alternative methods as in Figure 6, results are satisfactory over the whole range of measurement (note that a linear scale is used in this graph). Predictions by Equation 21 fit satisfactorily well with measurements at GWK (average $F_{h, i m p}$ Measured/Predictied $\simeq 1$ ) while they overestimate the HRW data by $\sim 60 \%$, probably due to the relatively low sampling rate $(400 \mathrm{~Hz})$ used during testing. 


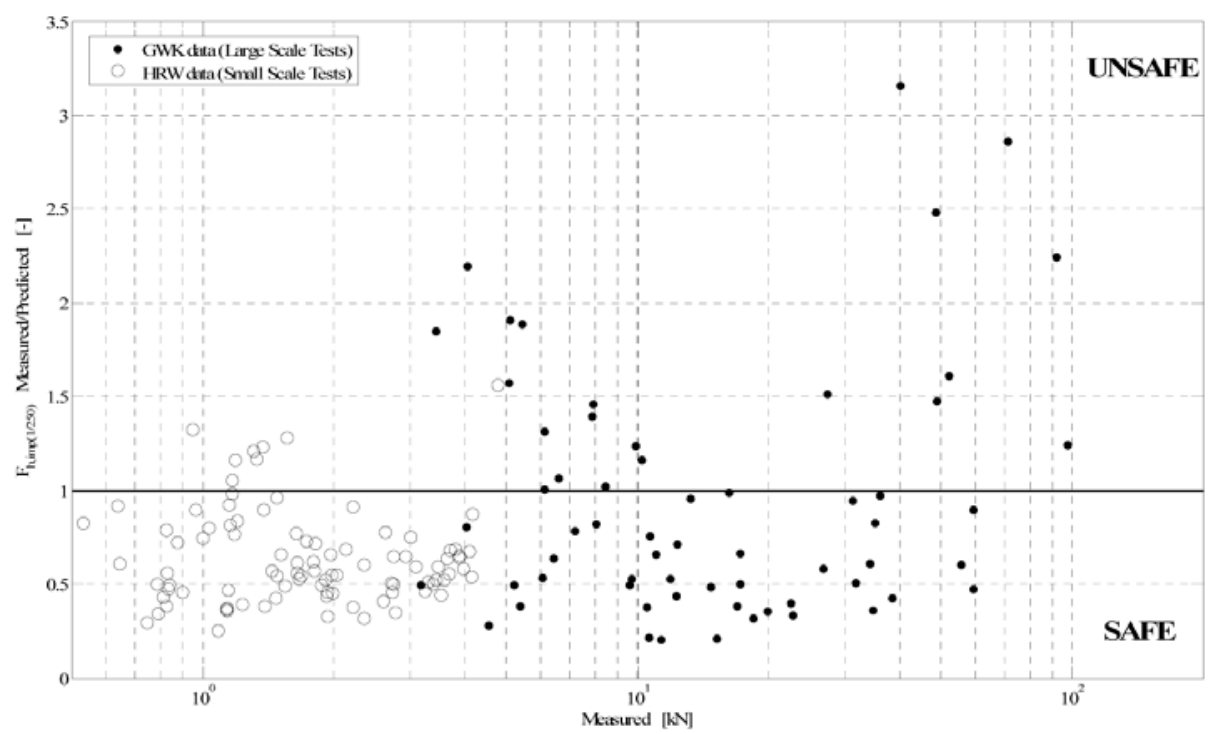

Figure $15 \quad$ Comparison of prediction by Equation 12 with (scaled) measurements of wave impacts at large and small scale from physical model tests at GWK and HRW under PROVERBS project.

\section{Pressure distribution up the wall}

It is generally assumed that the maximum pressure occurs at the still water level (s.w.l.). Hull and Müller (2002) made a large number of observations on breaker heights, shapes and pressures at seawalls. It was reported that the magnitude and location of pressure maxima vary accordingly to the breaker type at the wall. The point of maximum pressure shifts from a position above the still water level (s.w.l.) for a wave on the point of breaking ("flip-through"), to the s.w.l. for breakers entrapping air pockets to below the s.w.l. for a plunging bore. Moreover, the authors warned that, although the maximum pressure corresponds to a large air pocket breaker and is localised at the s.w.I., when a flip-through occurs, local pressures above the s.w.I. can be higher than those generated by a large air pocket breaker at the same location. Observations of pressure distribution on the wall as recorded during model tests on sea walls are presented in the following, in terms of spatial variability of both pulsating (quasi-static) and impact pressures.

\subsection{Quasi-static pressures}

Dimensionless quasi-static pressures $\left(P_{q s, 1 / 250} / \rho g H_{m 0}\right)$ recorded by the vertical array of pressure transducers during the Big-VOWS physical model tests are plotted in Figure 16. The relative location of the transducers up the wall is normalised by $\left(z_{k}-d\right) / H_{m 0}$, where $z_{k}=0.1 \mathrm{~m}+(k-1) 0.2 \mathrm{~m}$ is the height (in meters) of the $k^{\text {th }}$ transducer above the toe of the wall. 


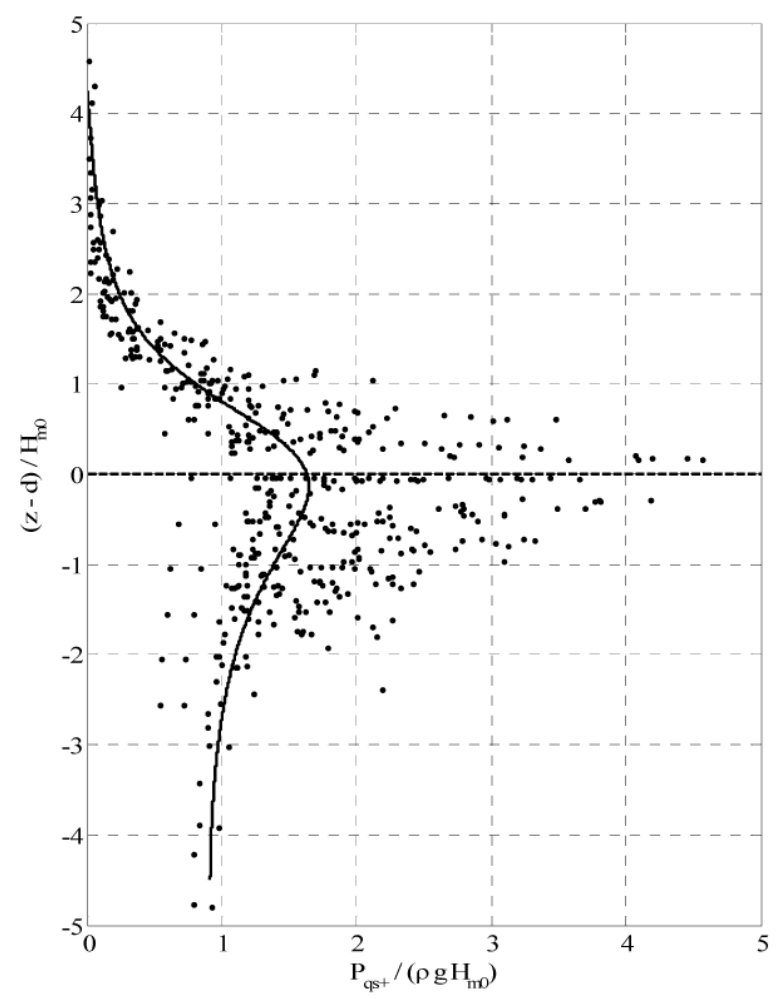

Figure 16 Spatial distribution of normalised quasi-static positive (shoreward) pressure as a function of the relative location of pressure transducers up the wall

The wave-induced quasi-static pressures tend to be relatively large up the wall, up to more than twice $\mathrm{H}_{\mathrm{m} 0}$ above the s.w.I. Tentative interpolating curves have been fitted and are superimposed to the experimental data. For shoreward $P_{q S^{+}}$pressures, the analytical expressions of curve on the left-hand side of Figure 16 is:

$$
P_{q s+(1 / 250)} / \rho g H_{m 0}=\frac{-0.054 \cdot y^{3}+0.43 \cdot y^{2}-1.4 \cdot y+2.7}{y^{2}-0.68 y+1.6}
$$

Equation 22 above is valid for $-4.5<y<4.5, R^{2}=0.4$.

It must be stressed that experimental data shown in Figure 16 are averaged over the four maximum values recorded during each test by each pressure sensor and thus relatively independent since they do not necessarily correspond to the same wave. Furthermore, since Equation 22 was fitted over the whole data set, it might under-estimate most intense loadings and under-estimate the lowest. For these reasons, they should not be employed as an alternative method for the evaluation of the overall load to be used in design. Accuracy of predictions by Equation 22 decreases near the still water level, with measured maximum pressures exceeding prediction by a factor of three. Nevertheless, use of Equations 22 with its corresponding safety factor (3x) is particularly useful and recommended when assessing the local stability of elements located up the wall, away from the s.w.l. (i.e., elements of blockwork structures, parapet walls, crownwalls...) and wave run-up on vertical or very steep walls. 


\subsection{Impact pressures}

Dimensionless impact pressures $\left(P_{i m p,(1 / 250)} / \rho g H_{m 0}\right)$ on the wall recorded during the physical model tests are plotted versus the relative elevation of the transducers $\left(z_{k}\left(z_{k}-d\right) / H_{m 0}\right.$ in Figure 16 for the two water depths, $d=0.53 \mathrm{~m}$ (left) and $d=0.83 \mathrm{~m}$ (right). As expected, pressure distribution on the wall at impact show much larger values accompanied by a much higher degree of scatter. Nevertheless, a few observations can be derived from Figure 16. At a water depth, $d=0.53 \mathrm{~m}$, most impacts resulted from breakers plunging against the wall trapping air pockets (confirmed by both video-recordings and noises during testing); experimental evidence in Figure 16 confirms that in these conditions maximum impact pressures occur at the s.w.I. (Hull and Müller 2002). During the tests carried out at $d=0.83 \mathrm{~m}$, a wider selection of breaker types reached the structure, as confirmed by the scatter of wave pressure maxima around the s.w.l.

\section{Pressure impulse}

Using the methodology described by McConnell \& Kortenhaus (1997), pressure impulses I on the wall were evaluated for the four severest force events within each 1000-wave test according to:

$$
\mathrm{I}=\frac{P_{i m p}}{2} \cdot\left(t_{i m p}-t_{0}\right)
$$

where $P_{\max }$ is the maximum pressure recorded by each transducer within an impact event, and $t_{i m p}$ and $t_{0}$ are respectively the time when the pressure reaches its maximum $P=P_{\text {imp }}$ and up-crosses the threshold of $P=$ $P_{\min }$ defined in Equation 11 (McConnell and Kortenhaus, 1997).

Pressure impulses were non-dimesionalised as $I / \rho H U$, where $H$ is a spatial scale of the event and $U$ is a water particle velocity in the crest of the wave. Averaged, minimum and maximum dimensionless pressure impulses from eight tests selected among the whole set of experiments are plotted in Figure 18 against relative elevation of the transducers up the wall $(z / d)$. 

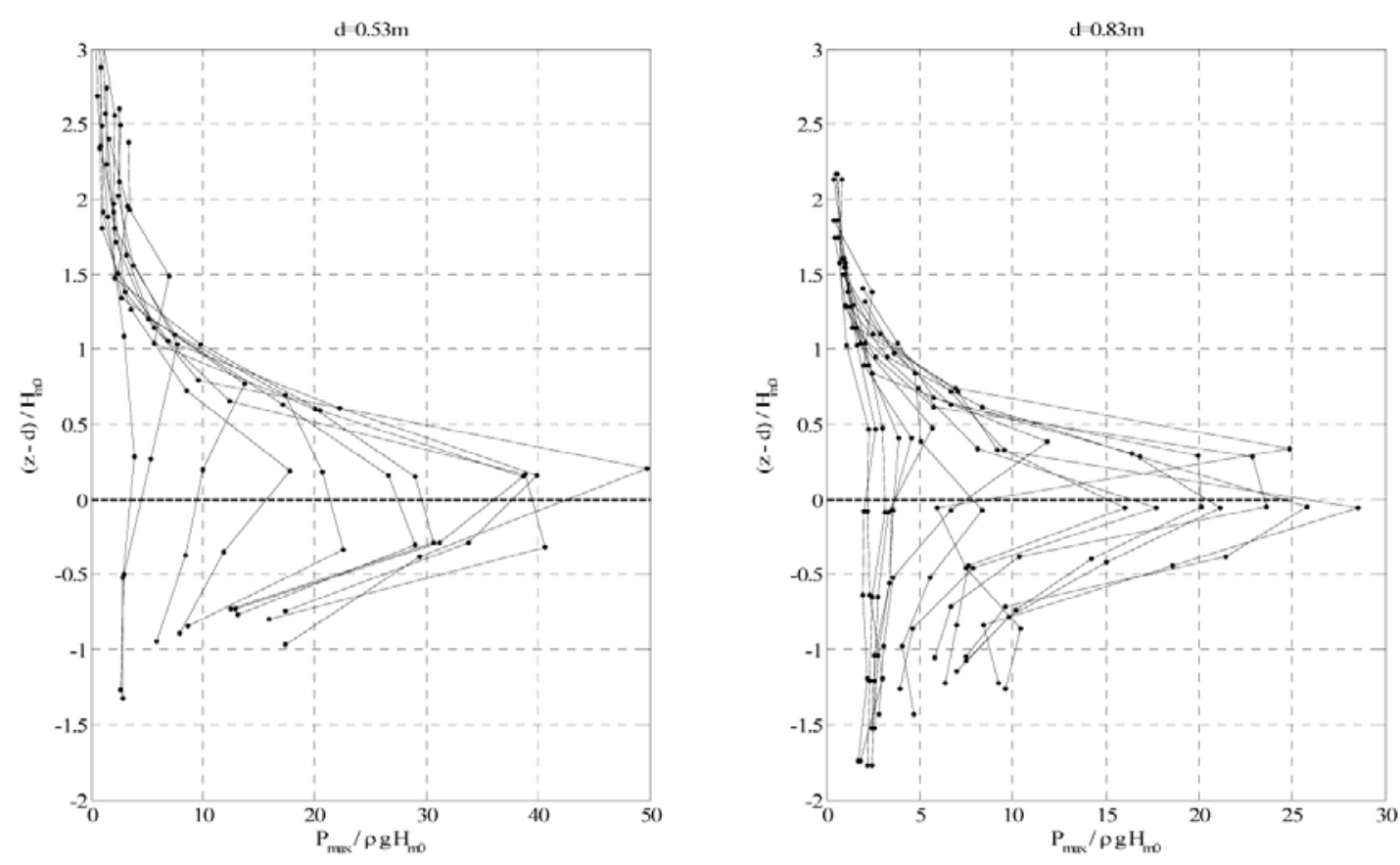

Figure $17 \quad$ Impact pressure distribution as a function of the relative location of pressure transducers up the wall; $d=0.53 m$ (left) and $d=0.83 m$ (right).

The pressures predicted by pressure-impulse theory assuming no air entrapment (Cooker and Peregrine, 1990b; dashed line) and wave bounce back (Wood et al., 2000; solid line), are also shown. As neither measurements of particle velocity nor air content had been taken during the experiments, the following assumption has been made in the calculation:

a the spatial scale $H$ has been taken as $H=d+H_{m 0} / 2$;

v the air pocket has been assumed to have diameter $A_{D}=H_{m 0} / 3$ and its centre to be located at $0.5 A_{D}$ above the s.w.l. (assuming a vertical asymmetry crest/trough of the wave profile at breaking of approximately $0.7 / 0.3$, Figure 12);

- the velocity scale $U$ has been assumed equal to the velocity of a solitary wave having height $H_{m o}$ and therefore velocity $U=u_{0}=\sqrt{g\left(d+H_{m 0}\right)}$ (Munk, 1949).

Due to the simplifications made in the computations, and the large variability of phenomena observed during the testing, the scatter of measurements around predictions was expected to be large. Nevertheless the comparison shows a relatively good agreement (within a factor of 2) of measurements with theoretical predictions, confirming wave pressure impulse to be a more consistent feature of impact loading than the pressure maxima, so pressure-impulse theory can be taken to represent a widely applicable method to the solution of water impact problems. 

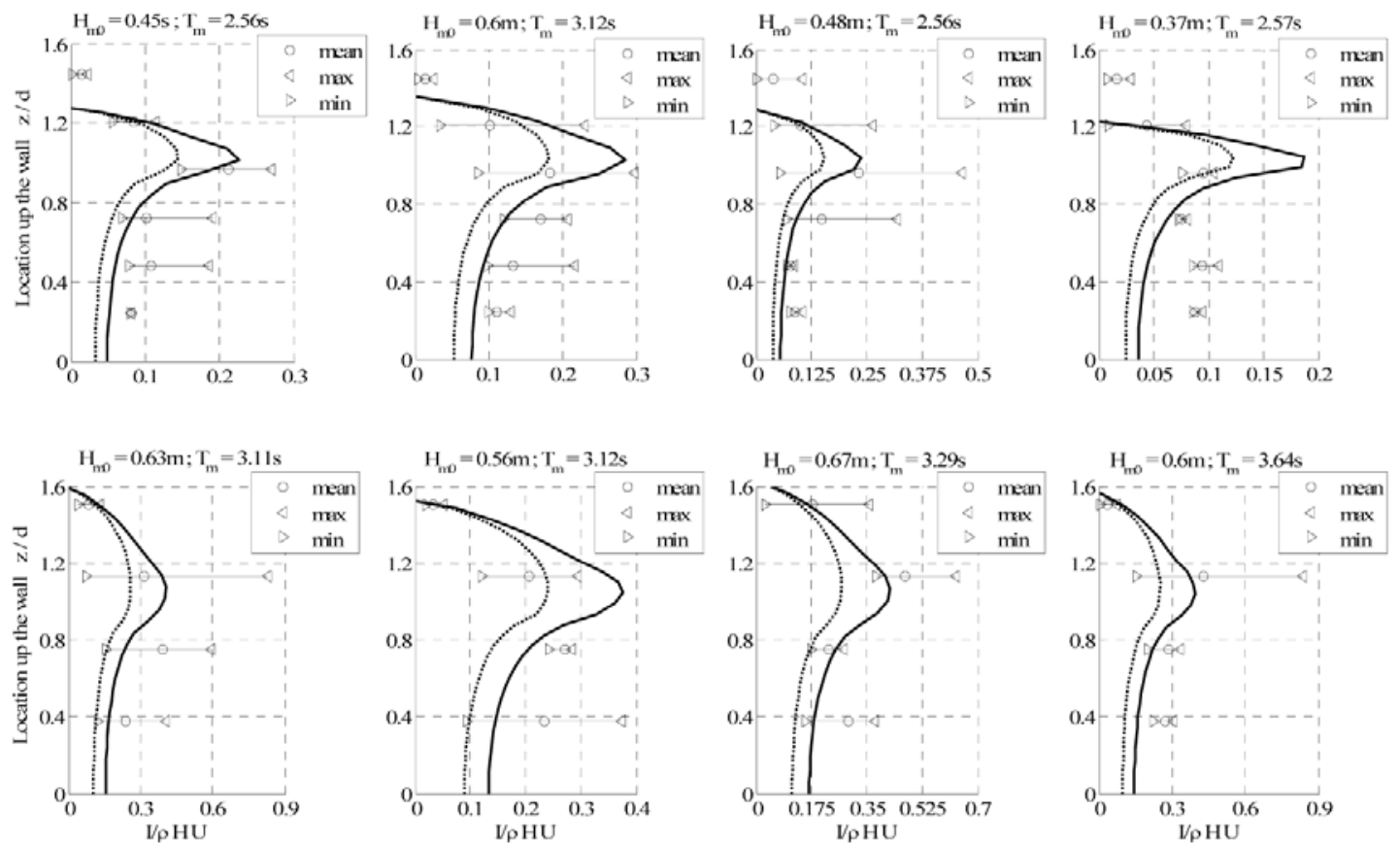

Figure $18 \quad$ Pressure impulse distribution up the wall. Predictions shown are Cooker and Peregrine (1990) without air (solid lines) and Wood et al. (2000) with "bounce back" (dashed lines).

\subsection{Impact rise-times}

Since wave impulse is a finite quantity, most intense wave impacts have shorter rise times $t_{r}=t_{i m p}-t_{0}$, This is confirmed in Figure 19 with impact maxima $F_{i m p}$ plotted versus their corresponding rise times $t_{r}$.

Based on conservation of momentum, the following semi-empirical relation between impact maxima and rise times has been proposed in the past by several authors:

$$
F_{i m p}=a \cdot t_{r}^{b}
$$

where $a$ and $b$ are empirical coefficients chosen so that Equation 24 envelopes scattered data such as in Figure 19. The solid line in Figure 19 obeys Equation 24 with $a=7$ and $b=-0.6$.

Largest impacts recorded during physical model tests have rise time $t_{r} \ll<0.05$ s but significant impacts were recorded with $t_{r}=\mathrm{O}(0.1 \mathrm{~s})$. Even after back-scaling to prototype scale such rise-times fall within the range of the natural periods of vibration $\left(T_{n}\right)$ of prototype structures $\left(0.05 \mathrm{~s}<T_{n}<1 \mathrm{~s}\right)$ and therefore the effective impact load to be used in design depends on the dynamic response of the structure that might amplify (for $\left.t_{r} \sim T_{n}\right)$ or (more likely) reduce $\left(t_{r}<<T_{n}\right)$ wave-induced loads. 


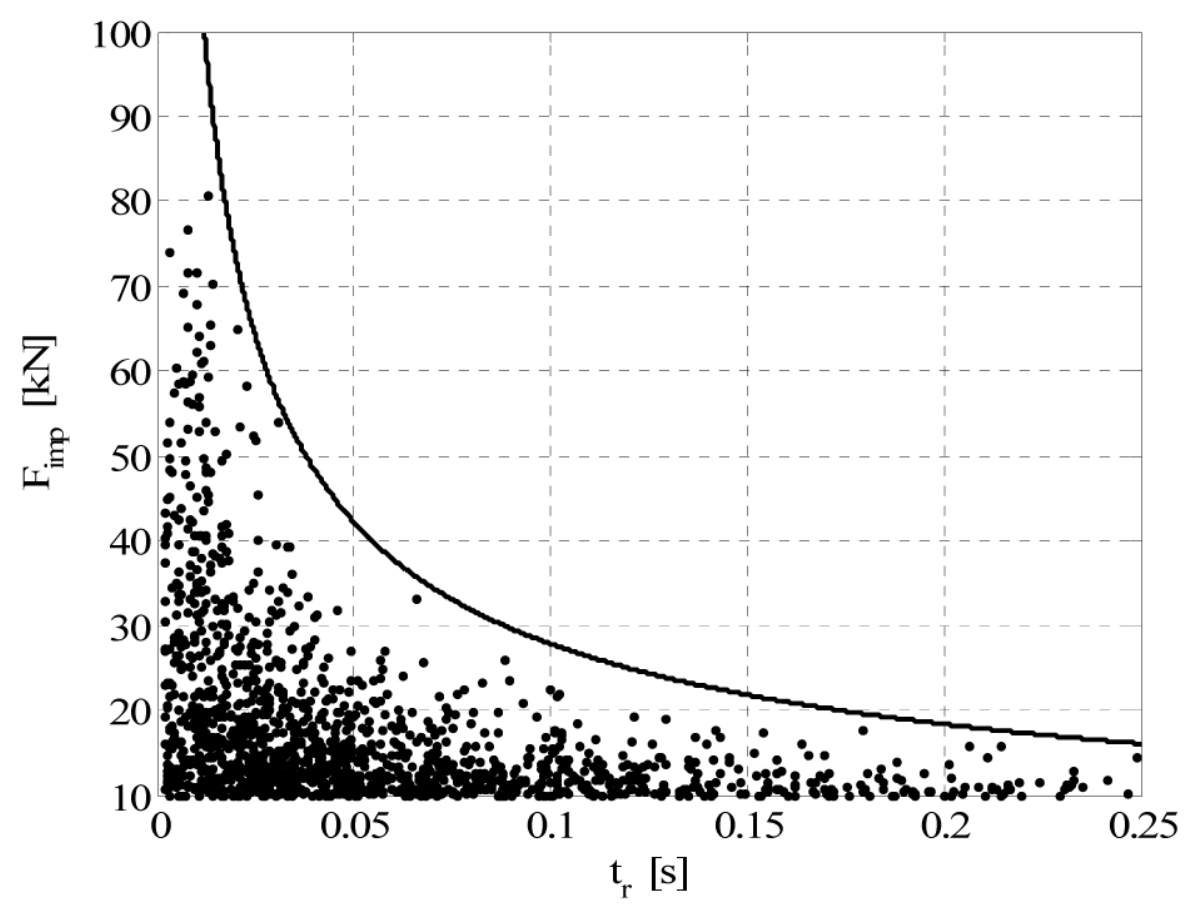

Figure 19 Impact force maxima and rise times recorded during physical model tests; solid line obeys Equation 24 with $\mathrm{a}=7$ and $\mathrm{b}=-0.6$.

\section{Conclusions and further work}

Detailed measurements of breaking wave pressures on a 10:1 battered seawall have been made in a large scale facility to study breaking wave effects on vertical face coastal structures such as seawalls and caissons breakwaters and to quantify the contribution of wave activity to both pulsating and impact loads on this kind of structures.

Comparison of new dataset with existing prediction methods highlighted large scatter in estimates of impact force maxima by previous study and significant underestimation of most severe loads, calling for the development of a new tool, based on physically rational basis.

Based on past and new observations, a set of physically-rational prediction formulae for both quasi-static and impact forces and overturning moments have been proposed, given by:

$$
\begin{aligned}
& F_{h, \text { imp (1/250) }}= \\
\text { - Impact: } & C_{r}^{1.65} \cdot \rho g \cdot H_{m 0} \cdot L\left(h_{s}\right) \cdot\left(1-\frac{\left|h_{b}-d\right|}{d}\right)
\end{aligned}
$$

- Quasi-static (shoreward): $F_{h, q s+(1 / 250)}=4.8 \cdot \rho g \cdot H_{m 0}^{2}$

Despite their simplicity, predictions by the above formulae compare more than satisfactorily with new observations over the whole range of parameter tested $\left(0.2 \mathrm{~m}<H_{m 0}<0.7 \mathrm{~m}, 0.5 \mathrm{~m}<d<1.3 \mathrm{~m}, 2.0 \mathrm{~s}<T_{\mathrm{m}}<3.7 \mathrm{~s}\right)$. Nevertheless, due to their empirical nature, application of the above equations is restricted to vertical and almost vertical structures on steep foreshore subject to breaking wave attack and recourse to other datasets is needed before the new formulae can be fully verified and calibrated to include effect of different structural geometry (e.g. composite vertical structures) and more complex wave attack (e.g. bimodal spectra; oblique 
incidence). Nevertheless, an initial comparison with measurements at small and large scales during PROVERBS gave encouraging results.

Shoreward pressure distribution up the wall have been derived from observations from physical model tests that can be used when assessing the local stability of elements located up the wall such as elements of blockwork structures, parapet walls and crownwalls.

Impact pressures distribution and duration is confirmed to depend on several mechanisms and to largely vary even under similar conditions. Using assumptions based on a mixture of past and present empirical observation and theoretical expressions from wave theory distribution of wave impulse up the wall at impact has also been derived and successfully compared with observations, confirming pressure-impulse theory to represent a widely applicable method to the solution of water impact problems.

Impacts recorded during physical model tests have rise times falling in the range of the natural periods of vibration of prototype structures. For such reason, after using Equation 13, the effective load for use in design should be corrected for the dynamic response of prototype structure. The stochastic nature of impact loading and scale effects should also be accounted for; guidance for the evaluation of the effective design load can be found in Oumeraci et al. (2001) an improved methodology has been recently formulated in Cuomo (2005), based on joint probability of impact force maxima and rise times.

\section{Acknowledgements}

This paper follows from work completed by HR Wallingford and academic researchers under a number of projects. Support by Universities of Rome 3, Edinburgh \& Southampton, HR Wallingford and the Marie Curie programme of the EU (HPMI-CT-1999-00063) are gratefully acknowledged. Previous research data were supported in UK by DTI under contracts PECD 7/6/263 \& 312, CI 39/5/96, and CI 39/5/125 (cc 1821), and PROVERBS (EC contract MAS3-CT95-0041). Nicolas Napp, supported by the UK EPSRC (GR/M42312) and Xavier Gironella and Javier Pineda (LIM UPC Barcelona), supported by EC programme of Transnational Access to Major Research Infrastructure, Contract no: HPRI-CT-1999-00066, are thanked for helping in collecting test data on wave forces at large scale. During testing at UPC, the VOWS team was joined by Dr Jordan Marinski from the Bulgarian Academy of Sciences, Sofia, and the authors are most grateful for his input to discussions and for his support.

\section{References}

Allsop, N.W.H., McBride, M.W. \& Colombo, D. (1994) "The reflection performance of vertical walls and 'low reflection' alternatives: results of wave flume tests" Proceedings 3rd Project Workshop, MAST II, MCSProject: Monolithic (Vertical) Coastal Structures, Emmeloord, The Netherlands, Paper 3.4,.

Allsop, N.W.H. (2000) Wave forces on vertical and composite walls, in "Handbook of Coastal Engineering" Edited by J. Herbich. New York: McGraw-Hill.

Allsop, N.W.H., McKenna, J.E., Vicinanza, D. \& Whittaker, T.J.T. (1996a) "New design formulae for wave loadings on vertical breakwaters and seawalls" Proc 25th Int. Conf. Coastal Engineering, pp 2508-2521, ASCE, New York.

Allsop N.W.H., Vicinanza D., Calabrese M. \& Centurioni L. (1996b) "Breaking wave impact loads on vertical faces" Proc. 6th International Offshore and Polar Engineering Conference (ISOPE 96), 3, pp185-191 
Allsop, N.W.H., Vicinanza, D. \& McKenna, J.E. (1996c) "Wave forces on vertical and composite breakwaters" Strategic Research Report SR 443, pp 1-94, HR Wallingford, March 1996, Wallingford.

Allsop, N.W.H. \& Vicinanza, D. (1996) "Wave impact loadings on vertical breakwaters: development of new prediction formulae" Proc. 11th Int. Harbour Congress, Antewerp, Belgium.

Allsop, N.W.H., Kortenhaus, A., Oumeraci, H. \& McConnell, K (1999) "New design methods for wave loading on vertical breakwaters under pulsating and impact conditions." Proc. Coastal Structures '99, Santander, Spain. Balkema Rotterdam, pp595-602.

Bagnold, R. A. (1939) "Interim report on wave pressure research" J. Institution of Civil Engineers $\underline{12}$, pp202-226.

Blackmore, P.A. \& Hewson, P.J. (1984) "Experiments on full-scale wave impact pressures" Coastal Engineering $\underline{8}, 331-346$.

British Standards BS-6349 (2000) "Maritime structures Part 1: Code of Practice for general criteria" BSI, London, UK.

Burcharth, H.F. \& Hughes, S.A. (2002) "Fundamentals of Design" in Coastal Engineering Manual, Part VI, Design of Coastal Project Elements, eds. Vincent, L. \& Demirbilek, Z., US Army Corps of Engineers, Washington D.C., chapter VI-5-2, Engineer Manual 1110-2-1100

Cooker, M. J. \& Peregrine, D. H. (1990a) "Computations of violent motion due to waves breaking against a wall” Proc. 22nd Int. Conf. Coastal Eng., Delft, The Netherlands., pp164-176, ASCE New York

Cooker, M. J. \& Peregrine, D. H. (1990b) "A model for breaking wave impact pressures" Proc. 22nd Int. Conf. Coastal Eng., Delft, The Netherlands., pp1473-1486, ASCE New York

Cooker, M. J. \& Peregrine, D. H. (1995) "Pressure-impulse theory for liquid impact problems" J. Fluid Mech. 297, pp193-214.

Cuomo, G. (2005) "Dynamics of wave-induced loads and their effects on coastal structures" PhD thesis, Science of Civil Engineering, University of Roma Tre, Italy.

Franco, L. (1994) "Vertical breakwaters: the Italian experience" Special Issue on vertical breakwaters, Coastal Engineering 22, pp31-55.

Gaillard, D. D. (1904) "Wave action in relation to engineering structures" Washington, D. C. U.S. Army Corps of Engineers.

Goda, Y. (1967) "The fourth order approximation to the pressure of standing waves" Coastal Eng. in Japan 10, pp1-11.

Goda, Y. (1974) "New wave pressure formulae for composite breakwater" Proc. of $14^{\text {th }}$ Int. Conf. Coastal Eng., Copenhagen, Denmark, pp1702-1720. ASCE New York,

Goda, Y. (2000) "Random seas and design of maritime structures (2nd Edition)", Advanced Series on Ocean Engineering - Vol. 15, World Scientific (443 pp).

Hiroi, I. (1920). "The force and power of waves." The Engineer, August, pp184-187.

Hull, P. \& Müller, G. (2002) "An investigation of breaker heights, shapes and pressures" Ocean Engineering 29, pp59-79. 
Kirkgoz, M.S. (1982) "Shock pressure of breaking waves on vertical walls"; Journal of Waterway, Port, Coastal and Ocean Division, 108, WW1, pp81-95, ASCE, New York.

Kirkgoz, M.S. (1983) "Secondary pressures of waves breaking on seawall" J. Waterways, Port, Coastal and Ocean Eng. 109, pp487-490.

Kirkgoz, M.S. (1990), "An experimental investigation of a vertical wall response to a breaking wave impact". Ocean Eng., 17, 4, pp 379-391

Kirkgoz, M.S. (1991) "Impact of breaking waves on vertical and sloping walls" Ocean Eng. 18, pp45-59,

Kirkgoz, M.S. (1992) "Influence of water depth on the breaking wave impact on vertical and sloping walls." Coastal Eng. 18, pp297-314.

Kirkgoz, M.S. (1995). IBreaking wave impact on vertical and sloping structures." Ocean Eng. 22:35-48.

Kirkgoz, M. S. \& Mamak, M. (2004) "Impulse modelling of wave impact pressures on vertical wall" Ocean Eng. 31, pp343-352.

Klammer, P., Kortenhaus, A. \& Oumeraci, H. (1996). "Wave impact loading of vertical face structures for dynamic stability analysis - prediction formulae." Proc. 25th Int. Conf. Coastal Eng., Orlando, Florida, USA, pp2534-2547,. ASCE New York

Kortenhaus, A., Oumeraci, H., Kohlhase, S. \& Klammer, P. (1994) "Wave induced up-lift loading of caisson breakwaters." Proc. 24 ${ }^{\text {th }}$ Int. Conf. Coastal Eng., Kobe, Japan, pp1298-1311, ASCE New York

Lundgren, H. (1969) "Wave shock forces: an analysis of deformations and forces in the wave and in the foundation" Proc. Symp. on Research in Wave Action. Delft Hydraulics Lab. Delft, The Netherlands, pp1-20.

McConnell, K.J. \& Kortenhaus, A. (1997) "Analysis of pressure measurements from hydraulic model tests and prototype measurements“, Proc. 1st overall project workshop, Las Palmas, Annex C3, PROVERBS project, Leichtweiss Institut, Technical University of Braunschweig, Braunschweig, Germany. MAST III.

McKenna, J.E. (1997) "Wave forces on caissons and breakwater crown walls" Ph.D thesis, Queen's University of Belfast, September 1997.

Miche, R. (1944) "Mouvements ondulatoires des mers en profondeur constante on decroissante" Ann. Des Ponts et Chaussees (in French)

Minikin, R. R. (1963) "Winds, Waves and Maritime Structures" $2^{\text {nd }}$ edition. London, UK: Charles Griffin.

Mitsuyasu, H. (1966) "Shock pressure of breaking waves" Proc. of $10^{\text {th }}$ Int. Conf. Coastal Eng., Tokyo, Japan. ASCE New York, 268-283.

Munk, W. H. (1949). "The solitary wave theory and its application to surf problems." Annales of the New York academy of sciences, pp378-424.

Oumeraci, H. (1994) "Review and analysis of vertical breakwater failures - lessons learned" Special Issue on vertical breakwaters, Coastal Engineering 22 pp3-29.

Oumeraci, H., Partenscky, H. W., Kohlhase, S. \& Klammer P. (1992) "Impact loading and dynamic response of caisson breakwaters - Results of large-scale model tests" Proc. $23^{\text {rd }}$ Int. Conf. Coastal Eng., Venice, Italy, pp1475-1488, ASCE New York 
Oumeraci, H., Klammer, P. \& Kortenhaus A. (1994) "Impact loading and dynamic response of vertical breakwaters - Review of experimental results -" Proc. of workshop on Wave Barriers in Deepwaters, Port and Airport Research Institute, Yokosuka, Japan, pp347-359

Oumeraci, H., Kortenhaus, A., Allsop, N.W.H., De Groot, M.B., Crouch, R.S., Vrijling, J.K. \& Voortman, H.G. (2001) "Probabilistic Design Tools for Vertical Breakwaters.",Balkema, Rotterdam (392 pp).

Pearson, J., Bruce, T. \& Allsop, N.W.H. (2002), "Violent wave overtopping - measurements at large and small scale", Proc. 28th lint. Conf. Coastal Eng., Cardiff, UK, pp2227-2238

Peregrine, D. H. \& Topliss, M. E. (1994) "The pressure field due to steep water waves incident on a vertical wall." Proc. 24th Int. Conf. Coastal Eng., Kobe, Japan. pp1496-1510, ASCE New York.

Sainflou, G. (1928) "Essai sur les digues maritimes verticals" Annales des Ponts et Chausse'es Paris $\underline{98}, 11$, pp:5-48 (in French),

Schmidt, R., Oumeraci H., \& Partenscky H. W. (1992) "Impact loading induced by plunging breakers on vertical structures." Proc. of $23^{\text {rd }}$ Int. Conf. Coastal Eng., Venice, Italy. ASCE New York, 1545-1558.

Stevenson, T. (1874) "The design and construction of harbors $2^{\text {nd }}$ edition". London: Black.

Takahashi, S. \& Hosoyamada, S. (1994) "Hydrodynamic characteristics of sloping top caissons." Proc. Int. Conf. on Hydro-Technical Eng. for Port and Harbour Construction. Port and Harbour Research Institute, Yokosuka, Japan, pp733-746.

Takahashi, S., Tanimoto, K. \& Shimosako, K. (1993) "Experimental study of impulsive pressures on composite breakwaters - Foundamental feature of impulsive pressure and the impulsive pressure coefficient" Rept. of Port and Harbour Research institute 31,.5, pp33-72 (in Japanese)

Tanimoto, K., Moto, K., Ishizuka, S. \& Goda Y. (1976) "An investigation on design wave force formulae of composite-type breakwaters." Proc. $23^{\text {rd }}$ Japanese Conf. on Coastal Eng. pp11-16 (in Japanese).

Topliss, M.E., Cooker, M.J. \& Peregrine, D.H. (1992) "Pressure oscillations during wave impact on vertical walls" Proc. of $23^{\text {rd }}$ Int. Conf. Coastal Eng., Venice, Italy, pp1639-1650 ASCE New York..

Walkden, M., Wood, D. J., Bruce, T. \& Peregrine, D. H. (2001) "Impulsive seaward loads on caisson breakwaters" Coastal Eng. 42, pp257-276.

Wood, D. J., Peregrine, D.H. \& Bruce, T. (2000) "Study of wave impact against a wall with pressure-impulse theory: Part I, Trapped air" J. of Waterways, Port, Coastal and Ocean Eng. 126 pp182-190. 